Working Paper

Series

National Centre of Competence in Research

Financial Valuation and Risk Management

Working Paper No. 371

\title{
Why Have Exchange-Traded Catastrophe Instruments Failed to Displace Reinsurance?
}

\author{
Rajna Gibson Michel Habib
}

Alexandre Ziegler

First version: February 2007

Current version: February 2007

This research has been carried out within the NCCR FINRISK projects on

"Corporate Finance, Market Structure and the Theory of the Firm" and "Credit Risk and Non-

Standard Sources of Risk in Finance" 


\title{
Why Have Exchange-Traded Catastrophe Instruments Failed to Displace Reinsurance?
}

\author{
Rajna Gibson* $\quad$ Michel Habib ${ }^{\dagger} \quad$ Alexandre Ziegler ${ }^{\ddagger}$
}

${ }^{*}$ Swiss Finance Institute, University of Zurich, Plattenstrasse 14, 8032 Zurich, Switzerland, tel.: +41(0)44-634-2969, fax: +41-(0)44-634-4903, e-mail: rgibson@isb.unizh.ch.

${ }^{\dagger}$ Swiss Finance Institute, University of Zurich, Plattenstrasse 14, 8032 Zurich, Switzerland, tel.: +41(0)44-634-2507, fax: +41-(0)44-634-4903, e-mail: habib@isb.unizh.ch; CEPR.

${ }^{\ddagger}$ Swiss Finance Institute, University of Lausanne, Extranef Building, 1015 Lausanne, Switzerland, tel.: +41-(0)21-692-3359, fax: +41-(0)21-692-3435, e-mail: alexandre.ziegler@unil.ch.

We wish to thank Pauline Barrieu, Henri Loubergé, and Avanidhar Subrahmanyam for useful comments and discussions, and Swiss Re for providing illustrative data. Financial support by the National Centre of Competence in Research "Financial Valuation and Risk Management" (NCCR FINRISK), the Swiss National Science Foundation (grant no. PP001-102717), and the URPP "Finance and Financial Markets" is gratefully acknowledged. 


\title{
Why Have Exchange-Traded Catastrophe Instruments Failed to Displace Reinsurance?
}

\begin{abstract}
In spite of the fact that they can draw on a larger, more liquid and more diversified pool of capital than the equity of reinsurance companies, financial markets have failed to displace reinsurance as the primary risk-sharing vehicle for natural catastrophe risk. We show that this failure can be explained by differences in information gathering incentives between financial markets and reinsurance companies. Using a simple model of an insurance company that seeks to transfer a fraction of its risk exposure either through financial markets or through traditional reinsurance, we find that the supply of information by informed traders in financial markets may be excessive relative to its value for the insurance company, causing reinsurance to be preferred. We show that whether traditional reinsurance or financial markets are ultimately selected depends crucially on the information acquisition cost structure and on the degree of redundancy in the information produced. Limits on the ability of informed traders to profitably take advantage of their information make the use of financial markets more likely.
\end{abstract}


Although the first reinsurance contract appeared in the marine industry in Genoa in 1370, professional reinsurance companies did not emerge until 1842, with the founding of the Cologne Reinsurance Company following a catastrophic fire in Hamburg in $1842 .{ }^{1}$ For over a century, professional reinsurance companies have been the preferred vehicle used by insurance companies to shed part of their catastrophe risk exposure.

Recently, traditional catastrophe reinsurance-viewed as an institutional vehicle to transfer catastrophe risk - has come under scrutiny in the academic literature. In his study of the market for catastrophe risk, Froot (2001) shows that insurers should optimally reinsure against large catastrophic events first. Moreover, since catastrophe risks are uncorrelated with aggregate financial wealth, reinsurance premia should reflect expected losses. Both of these conjectures are invalidated by his study of the aggregate profile of reinsurance purchases: insurers tend to reinsure medium-size losses, but retain (rather than reinsure) their large-event risks. Furthermore, the reinsurance premia they pay often are a multiple of expected losses. The author explains these phenomena mainly by the inefficiencies that characterize the supply of capital to reinsurance companies and by these companies' excessive market power. According to Doherty (1997), these inefficiencies of the reinsurance market should spur the development of alternate forms of risk transfer, such as securities traded on financial markets. Because financial markets can draw on a larger, more liquid and more diversified pool of capital than the equity of reinsurance companies, they should have a strong advantage over reinsurance in financing catastrophe risk.

The 1990s saw the development of a whole series of exchange-traded and over-thecounter catastrophe risk products. Catastrophe derivatives were first introduced at the Chicago Board of Trade (CBOT) in 1992. These exchange-traded derivatives were based on underlying indexes that reflected insurance property losses. They consisted primarily of futures and options written on futures contracts. Due to very low trading activity, these contracts were replaced in 1995 by catastrophe spread options on loss indexes provided by the Property Claim Services (PCS); these options themselves were withdrawn in 2000 due to low interest. Low trading volume and large bid-ask spreads also characterized

\footnotetext{
${ }^{1}$ An overview of the history of the reinsurance industry can be found in Swiss Re (2002).
} 
catastrophe index options traded on the Bermuda Commodities Exchange, a dedicated exchange that opened in late 1997. Trading was suspended in August 1999, and the exchange was eventually liquidated. Although off-exchange, privately placed catastrophe bonds, first introduced in 1994 by Hannover Re, have been more successful, they too are characterized by large bid-ask spreads, and their share of the reinsurance market remains limited: at the end of 2004, these bonds' outstanding risk capital represented less than $10 \%$ of total insured losses (Sigma, 2006).

In this study, we argue that differences in information gathering incentives between financial markets and reinsurance companies can explain why, over a decade after the introduction of the first insurance-linked securities, financial markets have not displaced reinsurance - despite the latter's alleged inefficiencies - as the primary risk-sharing vehicle for natural catastrophe risk. We consider a simple model where an insurance company seeks to transfer a fraction of its natural catastrophe risk exposure either through the financial market or through traditional reinsurance, selecting the form of risk transfer that has the lowest cost. Better information about the exposure decreases the amount of capital that must be held by the insurance company, either for regulatory reasons or for risk management purposes. Information acquisition - whether by the reinsurer or by informed traders in the financial market-is costly, and the cost of the information produced ultimately is borne by the insurer. Building on the Subrahmanyam and Titman (1999) model of the choice between private and public equity, we characterize the optimal information acquisition policy of informed traders and the reinsurer. We find that the financial market may display a Hirshleifer (1971) effect in the sense that the production of information by informed traders is excessive relative to its value for the insurance company. Not wishing to pay the cost of excessive information acquisition, the insurer favors reinsurance over the financial market.

Of course, the same argument could be made for share and bond issues. What distinctive features of catastrophe risk makes excessive information acquisition a problem for insurance linked securities but not for shares and bonds? We believe that the key differences are the information acquisition cost structure and the degree of redundancy in 
the information produced. Indeed, as does that of Subrahmanyam and Titman (1999, p. 1074) for corporate financing, our model highlights the importance of the cost of obtaining information and of the diversity of that information on the optimal information gathering channel for natural catastrophe risk transfer: public (financial markets) versus private (reinsurance).

In contrast to Subrahmanyam and Titman (1999), who consider investors that can only acquire a signal of a given precision, our model distinguishes fixed and variable information acquisition costs: each agent can acquire a signal of a certain (minimum) precision by incurring a fixed cost, and can further refine the precision of his information by incurring variable costs. We find that the size of the fixed cost and the relative magnitude of the fixed and variable costs-i.e., the degree of convexity in the information acquisition cost structure-are key determinants of the preferred form of risk transfer. When the fixed cost is large, information acquisition by multiple traders in the financial market is too costly, and reinsurance is preferred. When the fixed cost is large compared to the variable cost, centralized information acquisition by the reinsurer is more efficient than decentralized information acquisition in the financial market, again favoring reinsurance. In contrast, when information acquisition costs are highly convex, information acquisition by several traders in the financial market is more efficient, and the financial market is preferred. Thus, large fixed information acquisition costs constitute a key explanation for the failure of exchange-traded catastrophe instruments. ${ }^{2}$

The second key determinant of the preferred form of risk transfer is the degree of redundancy in the information produced. To motivate the concept of information redundancy, contrast two phenomena, one well-understood and the other much less so. An example of the former may be the profitability of a firm; an example of the latter may be global warming. If it were possible to aggregate all available information about one and the other phenomena, for example through trading in a financial market, it is likely that much less uncertainty would remain about the first phenomenon than the second. The same holds true of financial securities whose payoffs depend on these phenomena. More

\footnotetext{
${ }^{2}$ According to illustrative data provided to us by Swiss Re, fixed information acquisition costs for a given catastrophe are in the order of several million dollars (see Section 3).
} 
concretely, the value of a share traded on a stock market is likely to be estimated much more precisely than the value of an insurance-linked security such as a catastrophe option traded on an option market. This means that much more of the information about the option is redundant than about the share. Indeed, if the information were not redundant, gathering increasing amounts of information would progressively reduce and eventually altogether eliminate the uncertainty about the value of the option. ${ }^{3}$

To investigate the role of information redundancy in detail, we assume that the information regarding insured losses that a reinsurer or a trader in the financial market can gather contains both a systematic and an idiosyncratic error component. We find that the insurer's preference for one source of risk transfer over the other depends crucially on the relative importance of these two components. If the systematic error component is large, then having numerous traders in the financial market produce information is not very valuable: since much of that information is redundant, aggregate uncertainty about the loss remains large. Reinsurance therefore dominates in this case. In contrast, when the systematic component is small, information acquisition by numerous traders in the financial market is valuable: since traders' errors are mostly uncorrelated, information aggregation in the financial market makes for drastically reduced aggregate uncertainty about the loss. Such a drastic reduction cannot be achieved through reinsurance, and the financial market therefore dominates. The large systematic error component in insured loss estimates therefore constitutes a second key explanation for the failure of exchange-traded catastrophe instruments. ${ }^{4}$

Besides the information acquisition cost structure and information redundancy, several factors affect the choice between financial markets and reinsurance. Generally, financial

\footnotetext{
${ }^{3}$ See the model in Section 1 for formal details.

${ }^{4}$ Recent experience indicates that the systematic error component in the estimates of losses associated with natural catastrophes is indeed large. For example, in the case of hurricane Katrina in 2005, all major loss prediction models appear to have omitted the same factors. According to Swiss Re (2006), "what the models didn't predict was the storm surge [...], the breaching of the now deemed inadequate levee system protecting New Orleans [...] and the ensuing flood. [...] All three catastrophe modellers have looked at the impact of the increased frequency of hurricanes, while issues such as storm surge and flooding, demand surge and wind damage functions have either been introduced or improved." (Emphasis added.)
} 
markets dominate if there are tight limits on the ability of informed traders to profit from their information, thereby decreasing traders' incentives to acquire information. For example, if there are few noise traders in the market, informed traders are not able to "camouflage" their trades. In contrast, reinsurance dominates when the standard deviation of losses is large. This is because informed traders perceive large profit opportunities, enter the financial market in large numbers, and acquire large amounts of information. Since the cost of gathering information is borne by the insurer, the financial market is more costly than reinsurance.

There is an extensive literature on the use of financial markets for transferring catastrophe risk. Such literature has examined the advantages of financial markets, emphasizing their risk disaggregation (Doherty and Schlesinger, 2002) and capital supply (Jaffee and Russell, 1997) properties, and their lack of exposure to moral hazard and to default risk (Doherty, 1997, and Lakdawalla and Zanjani, 2006). In view of the very limited success of financial markets in transferring catastrophe risk, a number of potential explanations have been investigated: transactions costs, basis risk, and behavioral factors. Froot (2001) rules out the first, and Cummins, Lalonde and Phillips (2004) find that using standardized contracts carries little basis risk for large insurers. Bantwal and Kunreuther (2000) suggest that ambiguity aversion, loss aversion, and uncertainty avoidance may account for the reluctance of investment managers to invest in catastrophe bonds. Barrieu and Loubergé (2006) argue that the use of catastrophe bonds can be made more attractive by protecting bond buyers against the simultaneous occurrence of a catastrophe and a market crash. Unlike Bantwal and Kunreuther (2000) and Barrieu and Loubergé (2006), whose explanations for the limited use of financial markets are demand-based, ours is supply-based.

The paper proceeds as follows. Section 1 presents our model of an insurer that seeks to transfer a fraction of the risks he has insured either through reinsurance or using the financial market, selecting the form of risk transfer that has the lowest cost. Section 2 investigates the effect of information redundancy on the insurer's preferred risk transfer vehicle. Section 3 numerically analyzes the impact of the main model parameters on the insurer's decision. Sections 4 concludes. 


\section{The Model}

We consider an insurer that has insured losses represented by an asset of an uncertain (negative) value. The insurer has to choose between ceding risk to the financial market or to a reinsurer. ${ }^{5}$ We assume that because moral hazard or adverse selection considerations that we have left unmodeled make it impossible to reinsure completely, the insurer can cede no more than a fraction $\bar{\tau}<1$ of the losses he has insured.

In order to motivate the ceding of risk, we assume that the insurer's access to information is limited and that he has higher net cost of capital than does the reinsurer. The insurer therefore cedes risk for two reasons. The first is to replace his own, more expensive capital by the cheaper capital of the reinsurer or the "free" capital of the financial market (the capital of the financial market is free in the sense of having a net cost of zero).

The second reason is to induce the party to whom risk has been ceded, be it the informed traders in the financial market or the reinsurer, to incur the cost of improving the quality of the information, either in order to profit from informed trading or in order to economize on costly capital. The information is communicated to the insurer either directly by the reinsurer or indirectly through the price in the financial market. The insurer can then make use of this information in order to decrease the level of costly capital he himself must hold. The cost of the information produced is ultimately borne by the insurer, either directly through the reinsurance premium or indirectly through a discount on the price of the securities issued in the financial market. The purpose of the discount is to compensate noise traders for the losses they will sustain to informed traders. Noise traders' losses equal the informed traders' gross profits. These in turn equal the cost of information production.

When selecting the form of risk transfer, the insurer therefore takes the differences in the cost of capital of both options into account and trades off the quality of the information obtained (which results in lower required capital) against its cost.

\footnotetext{
${ }^{5}$ Although we consider the problem faced by a primary insurer for concreteness, the analysis is identical for a reinsurer choosing between retrocession and the financial market, or for a firm choosing between insurance and the financial market.
} 
The remainder of this section describes the details of the model. Section 1.1 describes the underlying information structure. Section 1.2 characterizes the structure of the financial market and informed traders' optimal information gathering decision. Section 1.3 presents the reinsurer's optimal information gathering decision. Section 1.4 derives the insurer' expected payoff for both risk transfer mechanisms.

\subsection{The Information Structure}

We assume that insured losses are represented by an asset that has value $\bar{l}+\delta$, with $\bar{l}<0$ and $\delta \sim N\left(0, v_{\delta}\right)$. Each agent $s$, which can be either a reinsurance company $r$ or an informed trader $n, n=1, \ldots, N$, can acquire information $i_{s}=\delta+\sqrt{v_{s}}\left(\gamma \xi+\sqrt{1-\gamma^{2}} \epsilon_{s}\right), 0 \leqslant \gamma \leqslant 1$. We assume $\xi \sim N(0,1), \epsilon_{s} \sim N(0,1), \operatorname{cov}(\delta, \xi)=\operatorname{cov}\left(\delta, \epsilon_{s}\right)=\operatorname{cov}\left(\xi, \epsilon_{s}\right)=\operatorname{cov}\left(\epsilon_{s}, \epsilon_{t}\right)=0$ for $s \neq t$.

The error in the information about losses consists of two parts, one perfectly correlated across agents, $\xi$, and the other perfectly uncorrelated, $\epsilon_{s}$. Any level of correlation between the error terms of two agents can therefore be obtained by varying the parameter $\gamma$. Indeed, we have

$$
\operatorname{corr}\left(i_{s}-\delta, i_{t}-\delta\right)=\operatorname{corr}\left(\gamma \xi+\sqrt{1-\gamma^{2}} \epsilon_{s}, \gamma \xi+\sqrt{1-\gamma^{2}} \epsilon_{t}\right)=\gamma^{2}
$$

We refer to $\gamma$ as the degree of redundancy in the information acquired. To provide some justification for our choice of terminology, consider the average error term across $N$ informed agents, $\frac{1}{N} \sum_{n=1}^{N} \sqrt{v_{n}}\left[\gamma \xi+\sqrt{1-\gamma^{2}} \epsilon_{n}\right]$. If $v_{n}=v$ for all $n$, its variance is

$$
\begin{aligned}
\operatorname{var}\left[\frac{1}{N} \sum_{n=1}^{N} \sqrt{v_{n}}\left[\gamma \xi+\sqrt{1-\gamma^{2}} \epsilon_{n}\right]\right] & =v\left[\frac{\gamma^{2}}{N^{2}} \operatorname{var}\left[\sum_{n=1}^{N} \xi\right]+\frac{1-\gamma^{2}}{N^{2}} \operatorname{var}\left[\sum_{n=1}^{N} \epsilon_{n}\right]\right] \\
& =v\left(\gamma^{2}+\frac{1-\gamma^{2}}{N}\right)
\end{aligned}
$$

Using that variance as a proxy for the uncertainty that remains once the information across all agents has been aggregated, we see that the larger $\gamma$, the smaller the decrease in aggregate uncertainty as more agents contribute information, i.e., the larger $\gamma$, the larger the redundancy in the information across agents. 
To provide some intuition for the role of $\gamma$ in the model, consider the two extreme cases $\gamma=0$ and $\gamma=1$. In the former case, the variance of the average error term disappears for $\gamma=0$ as $N \rightarrow \infty$ : there is no aggregate uncertainty when a large enough number of agents can be called upon to contribute their information. In the latter, the variance of the average error term is unaffected by $N$ : aggregate uncertainty remains regardless of the number of agents contributing information. We view the former case as representing well understood risks such as mortality risk (assuming new diseases such as AIDS do not render established mortality tables obsolete). Whilst no agent alone has a complete picture of the risk, all agents together do. We view the latter case as representing those risks that are still poorly understood, such as some forms of catastrophe risk. As mentioned in the introduction, there is evidence that the systematic error component in the estimates of losses associated with natural catastrophes - the redundancy in the information - is indeed large.

We allow $v_{s}$ to be chosen by agent $s$ and assume that the agent's information acquisition cost consists of a fixed and a variable component. By incurring a fixed cost of $k$, agent $s$ can acquire a signal with error variance $v_{s}=\bar{v}$, i.e., $1 / \bar{v}$ is the minimum precision of the information that can be acquired. The agent can then improve his understanding of the risk, i.e., refine the quality of his information by decreasing the variance of the error term to $v_{s}<\bar{v}$, at a variable cost $c\left(\bar{v} / v_{s}-1\right)$. The agent's total cost of acquiring information is therefore $c\left(\bar{v} / v_{s}-1\right)+k \cdot{ }^{6}$ Note that information acquisition by agent $s$ decreases the variance of the entire error term, reducing both correlated and uncorrelated errors, in the same proportion.

Note also that we assume that the reinsurer and informed traders can acquire the same information, at the same cost. Of course, given modeling expertise acquired and

\footnotetext{
${ }^{6}$ As in Subrahmanyam and Titman (1999; p. 1060), and in the line of Grossman and Stiglitz (1980), we assume that each agent acquires a single signal. This being said, the ability of each agent to improve the quality of his information by decreasing $v_{s}$ is equivalent to allowing him to obtain additional signals, each with variance $\bar{v}$. In the case where $\gamma=0$, our formulation amounts to assuming that the first signal costs $k$ and each subsequent signal $c$. More generally, for arbitrary $\gamma$, our formulation amounts to assuming that the first signal costs $k$ and the $M$ th signal $c\left(1-\gamma^{2}\right) /\left(\left(M \gamma^{2}+1\right)\left((M-1) \gamma^{2}+1\right)\right)$. We choose the formulation $c\left(\bar{v} / v_{s}-1\right)+k$ for tractability.
} 
customer data accumulated over decades of operation, reinsurers may be endowed with better information or have lower information acquisition costs than even sophisticated traders in financial markets. However, since our purpose is to explain the dominance of reinsurance over the financial market, we do not wish to build an advantage for reinsurance into the assumptions of the model.

\subsection{The Financial Market}

In this section, we describe the structure of the financial market that we consider and investigate information acquisition if the insurer decides to transfer risk by issuing insurance linked securities on the financial market. ${ }^{7}$ The structure that we use closely follows Subrahmanyam and Titman (1999), who generalize Kyle (1985). The financial market consists of $N$ informed traders, who base their demand on their information, and of noise traders with demand $z$ uncorrelated with all other variables, $z \sim N\left(0, v_{z}\right)$. Prices are set by a competitive risk-neutral market maker who expects to earn zero profit conditional on his information set. We are interested in determining the number of traders that choose to become informed, $N$, the precision of the information they choose to acquire, $1 / v$, and the information reflected in the price.

Recall that an informed trader $n$ receives information $i_{n}=\delta+\sqrt{v_{n}}\left(\gamma \xi+\sqrt{1-\gamma^{2}} \epsilon_{n}\right)$, where $\delta$ is the uncertain amount of the loss. We conjecture an equilibrium in which trader $n$ submits an order of the form $x_{n}=\kappa_{n} i_{n}$ and the market maker sets a price $P=\bar{\tau} \bar{l}+E[\bar{\tau} \delta \mid Q]=\bar{\tau} \bar{l}+\zeta Q$, where

$$
Q=x_{n}+\sum_{\substack{m=1 \\ m \neq n}}^{N} \kappa i_{m}+z=x_{n}+\sum_{\substack{m=1 \\ m \neq n}}^{N} \kappa\left(\delta+\sqrt{v}\left(\gamma \xi+\sqrt{1-\gamma^{2}} \epsilon_{m}\right)\right)+z
$$

denotes the total order flow received by the market maker, including noise trader demand $z$. Note that we consider a symmetric equilibrium, in which $\kappa$ and $v$ are the same for all traders.

\footnotetext{
${ }^{7}$ Note that we do not consider the problem of optimally designing these securities. For an analysis of optimal security design, see for example Boot and Thakor (1993), DeMarzo and Duffie (1999), and Fulghieri and Lukin (2001).
} 
Naturally, trader $n$ takes the demand and the (inverse) quality of the information of the other traders as given when choosing his own demand $x_{n}$ and his (inverse) quality of information $v_{n}$. Hence, in choosing $x_{n}$, trader $n$ solves

$$
\begin{aligned}
\max _{x_{n}} E\left[x_{n}[\bar{\tau} \bar{l}+\bar{\tau} \delta-P] \mid i_{n}\right] & \equiv \max _{x_{n}} E\left[x_{n}[\bar{\tau} \delta-\zeta Q] \mid i_{n}\right] \\
& \equiv \max _{x_{n}} E\left[x_{n}\left[\bar{\tau} \delta-\zeta\left(x_{n}+\sum_{\substack{m=1 \\
m \neq n}}^{N} \kappa i_{m}+z\right)\right] \mid i_{n}\right]
\end{aligned}
$$

Solving for $x_{n}$ (the details are in the appendix), we have

$$
x_{n}=\kappa_{n} i_{n}=\kappa_{n}\left(\delta+\sqrt{v_{n}}\left(\gamma \xi+\sqrt{1-\gamma^{2}} \epsilon_{n}\right)\right)
$$

where

$$
\kappa_{n}=\frac{1}{2 \zeta} \frac{\bar{\tau} v_{\delta}-\zeta(N-1) \kappa\left(v_{\delta}+\gamma^{2} \sqrt{v_{n}} \sqrt{v}\right)}{v_{\delta}+v_{n}}
$$

In choosing $v_{n}$, trader $n$ uses $x_{n}$ obtained in (5) to solve

$$
\max _{v_{n}} E\left[E\left[x_{n}\left[\bar{\tau} \delta-\zeta\left(x_{n}+\sum_{\substack{m=1 \\ m \neq n}}^{N} \kappa i_{m}+z\right)\right] \mid i_{n}\right]\right]-c\left(\frac{\bar{v}}{v_{n}}-1\right)-k
$$

subject to the constraint $0 \leq v_{n} \leq \bar{v}$. In so doing, trader $n$ treats $\kappa, \zeta$, and $v$ as constant. We show in the appendix that in a symmetric equilibrium $\left(v_{n}=v\right)$, we have

$$
\begin{gathered}
\zeta=\frac{\bar{\tau} v_{\delta} \sqrt{N\left(v_{\delta}+v\right)}}{\sqrt{v_{z}}\left[(N+1) v_{\delta}+\left(2+(N-1) \gamma^{2}\right) v\right]} \\
\kappa=\sqrt{\frac{v_{z}}{N\left(v_{\delta}+v\right)}}
\end{gathered}
$$

and that the first-order condition for $v$ is

$$
\frac{\bar{\tau}\left(2+(N-1) \gamma^{2}\right) \sqrt{v_{z}} v_{\delta}}{2 \sqrt{N} \sqrt{v_{\delta}+v}\left[(N+1) v_{\delta}+\left(2+(N-1) \gamma^{2}\right) v\right]}=c \frac{\bar{v}}{v^{2}}
$$

Consider first the price impact of order flow, $\zeta$ in (8). The larger noise trading variance, $v_{z}$, the greater the importance of noise trader demand in order flow, and the lower therefore the price impact of order flow. The greater information redundancy, $\gamma$, the more intense the competition between informed traders, and the lesser therefore the price impact. The larger the number of informed traders, $N$, the more intense the competition between them; 
the larger also the pool of information in the order flow. The former effect decreases $\zeta$; the latter increases it. Which effect dominates depends on $N$ : when $N>N^{*} \equiv$ $1+2\left(1-\gamma^{2}\right) v /\left(v_{\delta}+\gamma^{2} v\right)$, the competition effect dominates and $\zeta$ decreases in $N$; the opposite is true when $N<N^{*} .8$ The greater the variance of losses $v_{\delta}$, the more the market maker stands to lose, and the greater therefore the price impact of order flow. ${ }^{9}$

This last effect is reflected in the aggressiveness with which informed traders respond to information, $\kappa$ in (9): foreseeing the large price impact of order flow, informed traders submit small orders when $v_{\delta}$ is large. In contrast, informed traders respond more aggressively to information, the greater the "camouflage" they are afforded by noise traders (large $v_{z}$ ), the lesser the competition between informed traders (small $N$ ), and the higher the quality of their information (low $v$ ).

Now consider the first-order condition (10). Greater noise trading variance, $v_{z}$, increases information acquisition in the financial market; as already noted, noise trading provides informed traders with the means to "camouflage" the trades they carry out in order to profit from the information they acquire. Greater information redundancy, $\gamma$, also increases information acquisition. ${ }^{10}$ To understand why, note that two properties of information make it valuable: its quality (low $v$ ), and its uniqueness (low $\gamma$ ). An informed trader responds to a decrease in the uniqueness of the information (higher $\gamma$ ) by increasing its quality (lower $v$ ) in an attempt to maintain its trading profits. A larger number of

\footnotetext{
${ }^{8}$ Note that $N^{*}$ decreases in $\gamma$ : the more correlated traders' information, the smaller the number of traders required for the competition effect to dominate.
}

${ }^{9}$ The effect of $v$ on $\zeta$ is ambiguous, since

$$
\frac{\partial}{\partial v}\left(\frac{\sqrt{v_{\delta}+v}}{(N+1) v_{\delta}+\left(2+(N-1) \gamma^{2}\right) v}\right)=\frac{\left((N-3)-2(N-1) \gamma^{2}\right) v_{\delta}-\left(2+(N-1) \gamma^{2}\right) v}{2 \sqrt{v_{\delta}+v}\left[(N+1) v_{\delta}+\left(2+(N-1) \gamma^{2}\right) v\right]^{2}}
$$

${ }^{10}$ To see this, note that

$$
\frac{\partial}{\partial\left(\gamma^{2}\right)}\left(\frac{2+(N-1) \gamma^{2}}{(N+1) v_{\delta}+\left(2+(N-1) \gamma^{2}\right) v}\right)=\frac{\left(N^{2}-1\right) v_{\delta}}{\left[(N+1) v_{\delta}+\left(2+(N-1) \gamma^{2}\right) v\right]^{2}}>0
$$


traders $N$ reduces information acquisition because competition erodes trading profits. ${ }^{11}$ Note also that since the left hand side of (10) tends to zero as $N$ becomes large, no trader will incur the cost of improving the quality of his information beyond $1 / \bar{v}$ in a financial market with a large number of informed traders: competition between traders drives the trader's expected profit to zero, thereby precluding him from recovering any cost he may have incurred and deterring him from incurring that cost in the first place. Finally, the quality of the information acquired, $1 / v$, is increasing in the fraction of risk ceded, $\bar{\tau}$, and in the starting quality of the information, $1 / \bar{v}$ : more at stake induces more information acquisition; information acquisition is impeded by lower quality starting information. ${ }^{12}$

As shown in the appendix, the expected profit of an informed trader is

$$
\Pi_{f}=\frac{\bar{\tau} \sqrt{v_{z}} v_{\delta} \sqrt{v_{\delta}+v}}{\sqrt{N}\left[(N+1) v_{\delta}+\left(2+(N-1) \gamma^{2}\right) v\right]}-c\left(\frac{\bar{v}}{v}-1\right)-k
$$

As one would expect, this profit is increasing in the fraction of risk ceded, $\bar{\tau}$, in the variance of noise trader demand, $v_{z}$, in the starting quality of information, $1 / \bar{v}$, and in the uncertainty about the loss, $v_{\delta}{ }^{13}$ It is decreasing in the number of traders $N$, in the fixed and variable costs of information acquisition, $k$ and $c$, and in the degree of information redundancy, $\gamma$. This last effect arises because - as is well-known from the auction literature (Milgrom and Weber, 1982) — traders earn larger profits from unique information than from common. Unique information is smaller, the larger $\gamma$.

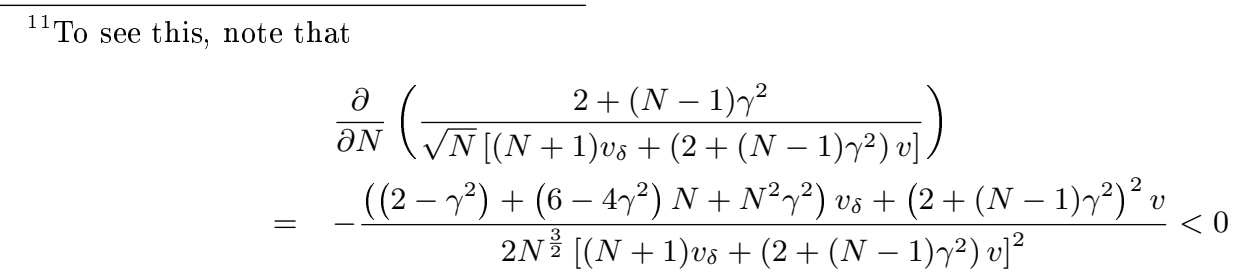

${ }^{12}$ The impact of uncertainty about the loss $v_{\delta}$ on the information acquired is ambiguous, since

$$
\frac{\partial}{\partial v_{\delta}}\left(\frac{v_{\delta}}{\sqrt{v_{\delta}+v}\left[(N+1) v_{\delta}+\left(2+(N-1) \gamma^{2}\right) v\right]}\right)=\frac{\left(2+(N-1) \gamma^{2}\right) v\left(v_{\delta}+2 v\right)-(N+1) v_{\delta}^{2}}{2\left(v_{\delta}+v\right)^{\frac{3}{2}}\left[(N+1) v_{\delta}+\left(2+(N-1) \gamma^{2}\right) v\right]^{2}}
$$

${ }^{13}$ We have

$$
\frac{\partial}{\partial v_{\delta}}\left(\frac{v_{\delta} \sqrt{v_{\delta}+v}}{(N+1) v_{\delta}+\left(2+(N-1) \gamma^{2}\right) v}\right)=\frac{(N+1) v_{\delta}^{2}+\left(2+(N-1) \gamma^{2}\right) v\left(3 v_{\delta}+2 v\right)}{2 \sqrt{v_{\delta}+v}\left[(N+1) v_{\delta}+\left(2+(N-1) \gamma^{2}\right)\right]^{2}}>0
$$


In equilibrium, the number of informed traders $N$ active in the market is such that $\Pi_{f}(N)=0$. Given the properties of $\Pi_{f}$, the equilibrium number of traders is larger, the higher $\bar{\tau}, v_{z}$ and $v_{\delta}$, and the smaller $\bar{v}, c, k$ and $\gamma$. The information contained in the price at equilibrium is that contained in the total order flow $Q$, as $P=\bar{\tau} \bar{l}+\zeta Q$. This information is

$$
Q=\kappa \sum_{n=1}^{N} i_{n}+z=N \kappa(\delta+\sqrt{v} \gamma \xi)+\kappa \sqrt{v} \sqrt{1-\gamma^{2}} \sum_{n=1}^{N} \epsilon_{n}+z
$$

The securities are issued at a discount to their expected value. The discount serves to compensate noise traders for the losses they will sustain to informed investors. It is endogenous and equals total information acquisition costs, $N(c(\bar{v} / v-1)+k){ }^{14}$

\subsection{The Reinsurer}

In this section, we investigate information acquisition if the insurer decides to transfer risk to the reinsurer. Let the reinsurer $r$ have net cost of capital $a_{r}$. Capital is needed by the reinsurer to maintain solvability in the face of greater than expected losses. We assume that for each unit of risk remaining (as measured by the standard deviation of losses after the reinsurer has acquired any additional information on the loss he deems desirable), the reinsurer requires $\lambda$ units of capital. Thus, in an unregulated environment, a higher $\lambda$ would reflect more cautiousness on the part of the reinsurer, while in a regulated environment, it would reflect more stringent capital requirements.

The reinsurer's capital has positive net cost because of information and incentive considerations (Froot, Scharfstein, and Stein, 1993; Froot and O'Connell, 1997; Froot and Stein, 1998; Gron and Winton, 2001). Note that, while capital is needed in the case of the financial market too, where it takes the form of margin requirements, it has zero net cost in that case. Indeed, because it is deposited in a margin account maintained by a clearinghouse rather than invested in the shares issued by a reinsurance company, capital

\footnotetext{
${ }^{14}$ Noise traders' expected losses equal $E((P-\bar{\tau} \bar{l}) z)=E(\zeta Q z)=\zeta v_{z}$. Using $(8)$ and $\Pi_{f}(N)=0$, we have

$$
\zeta v_{z}=\sqrt{v_{z}} \frac{\bar{\tau} v_{\delta} \sqrt{N\left(v_{\delta}+v\right)}}{(N+1) v_{\delta}+\left(2+(N-1) \gamma^{2}\right) v}=N\left(c\left(\frac{\bar{v}}{v}-1\right)+k\right)
$$
}


in the financial market involves neither information nor incentive considerations. ${ }^{15}$

As mentioned in Section 1.1, we assume that the reinsurer can acquire the same information as an informed trader, at the same cost. The problem solved by the reinsurer who is assumed to reinsure a fraction $\bar{\tau}$ of insured losses $\bar{l}+\delta$ is

$$
\begin{aligned}
& \max _{v_{r}} \bar{\tau}\left(\bar{l}-\lambda a_{r} S D\left[\delta \mid \delta+\sqrt{v_{r}}\left(\gamma \xi+\sqrt{1-\gamma^{2}} \epsilon_{r}\right)\right]\right)-c\left(\frac{\bar{v}}{v_{r}}-1\right)-k \\
= & \max _{v_{r}} \bar{\tau}\left(\bar{l}-\lambda a_{r}\left[v_{\delta}-\frac{v_{\delta}^{2}}{v_{\delta}+v_{r}}\right]^{\frac{1}{2}}\right)-c\left(\frac{\bar{v}}{v_{r}}-1\right)-k
\end{aligned}
$$

where $S D[\cdot]$ denotes the standard deviation of losses after incorporating any information acquired, subject to the constraint $0 \leq v_{r} \leq \bar{v}$. Note that the amount of capital needed, as represented by $\lambda$ times the conditional standard deviation, is decreasing in the quality of the information acquired, $1 / v_{r}$.

In the case of an interior solution, problem (13) has first-order condition

$$
\frac{\bar{\tau} \lambda a_{r}}{2} \frac{v_{\delta}^{\frac{3}{2}}}{\left(v_{\delta}+v_{r}\right)^{\frac{3}{2}} v_{r}^{\frac{1}{2}}}=c \frac{\bar{v}}{v_{r}^{2}}
$$

Solving and imposing the constraint $v_{r} \leq \bar{v}$ yields

$$
v_{r}=\min \left[\bar{v}, \frac{v_{\delta} \phi}{v_{\delta}-\phi}\right], \quad \phi \equiv\left(\frac{2 c \bar{v}}{\bar{\tau} \lambda a_{r}}\right)^{\frac{2}{3}}
$$

Observe that more variable losses, $v_{\delta}$, induce more information acquisition by the reinsurer. In contrast, since there is a single reinsurer, the degree of information redundancy $\gamma$ has no impact on the reinsurer's optimal information acquisition strategy. Observe also that since $\partial v_{r} / \partial \phi \geq 0$, a greater net cost of capital, $a_{r}$, and more stringent capital requirements, $\lambda$, induce more information acquisition by the reinsurer, as higher quality information serves to economize on costly capital. Finally, as in the case of the financial market, the quality of the information acquired, $1 / v_{r}$, is increasing in the fraction of risk ceded, $\bar{\tau}$, and in the starting quality of the information, $1 / \bar{v}$.

\footnotetext{
${ }^{15}$ The net cost of capital $a_{r}$ includes any discount at which the reinsurance company's shares are issued. Any such discount is likely to be smaller than the discount on the insurance linked securities considered in Section 1.2, because of diversification within the reinsurance company. This is the direct analogue to Subrahmanyam (1991) and Gorton and Pennacchi's (1993) comparison of individual stocks and stock market indices.
} 
It is instructive to compare $v_{r}$ in (15) with $v$ in (10). It is possible to obtain both $v_{r}>v$ and $v_{r}<v$. To obtain the former, increase $v_{z}$ and concurrently increase $k$ to keep $N$ constant. For $v_{z}$ large enough, there will be a $v<v_{r}$. To obtain the latter, let $k$ be so small and therefore $N$ so large as to make $v=\bar{v}$. For large $a_{r}, v_{r}$ will be less than $\bar{v}$ and therefore less than $v$.

\subsection{The Insurer}

Having analyzed the information gathering incentives of informed traders in the financial markets and of the reinsurer, we can now determine the expected cost to the insurer of using financial markets or reinsurance to transfer risk.

The expected cost to the insurer of ceding a fraction $\bar{\tau}$ of the losses to the financial market is that fraction of the expected loss $\bar{l}$ plus the combined cost of information acquisition by informed traders, i.e., $\bar{\tau} \bar{l}-N(c(\bar{v} / v-1)+k)$ (recall that $\bar{l}<0)$. The benefit is a reduction in the required amount of capital arising from the fact that the insurer only retains a fraction $1-\bar{\tau}$ of the risk, and from the improved quality of the information. Hence, letting $a_{i}$ denote the insurer's cost of capital and assuming, as for the reinsurer, that the insurer must hold $\lambda$ units of capital for each unit of risk remaining, the insurer's expected payoff from using the financial market for ceding risk is

$$
\begin{aligned}
\Gamma_{i, f} & =(1-\bar{\tau}) \bar{l}-\lambda a_{i}(1-\bar{\tau}) S D[\delta \mid Q]+\bar{\tau} \bar{l}-N\left(c\left(\frac{\bar{v}}{v}-1\right)+k\right) \\
& =\bar{l}-\lambda a_{i}(1-\bar{\tau}) \sqrt{v_{\delta}}\left[1-\frac{N v_{\delta}}{(N+1) v_{\delta}+\left(2+(N-1) \gamma^{2}\right) v}\right]^{\frac{1}{2}}-N\left(c\left(\frac{\bar{v}}{v}-1\right)+k\right)
\end{aligned}
$$

where the second equality follows from (9) and (12), $v$ is the solution to (10), and $N$ is obtained from the zero profit condition $\Pi_{f}(N)=0$. Note that the price is more informative $(S D[\delta \mid Q]$ is smaller), the larger the number of traders, $N$, the higher the quality of their information, $1 / v$, and the lower the degree of redundancy in the information produced, $\gamma$. The variance of noise trader demand, $v_{z}$, has no direct impact on price informativeness, but has an indirect effect through its impact on the equilibrium number of traders $N$ and the quality of the information they acquire $1 / v$. 
Similarly, the expected cost to the insurer of ceding a fraction $\bar{\tau}$ of the losses to the reinsurer is that fraction of the expected loss $\bar{l}$, plus the reinsurer's capital cost, plus his information acquisition cost, i.e., $\bar{\tau} \bar{l}-\lambda a_{r} \bar{\tau} S D\left[\delta \mid i_{r}\right]-c\left(\bar{v} / v_{r}-1\right)-k$. The benefit is again a reduction in the required amount of capital. Hence, the insurer's expected payoff from ceding risk to the reinsurer is

$$
\begin{aligned}
\Gamma_{i, r} & =(1-\bar{\tau}) \bar{l}-\lambda a_{i}(1-\bar{\tau}) S D\left[\delta \mid i_{r}\right]+\bar{\tau} \bar{l}-\lambda a_{r} \bar{\tau} S D\left[\delta \mid i_{r}\right]-c\left(\frac{\bar{v}}{v_{r}}-1\right)-k \\
& =\bar{l}-\lambda\left[a_{i}(1-\bar{\tau})+a_{r} \bar{\tau}\right] \sqrt{v_{\delta}}\left[1-\frac{v_{\delta}}{v_{\delta}+v_{r}}\right]^{\frac{1}{2}}-c\left(\frac{\bar{v}}{v_{r}}-1\right)-k
\end{aligned}
$$

where $v_{r}$ is given by (15).

\section{A First Look at the Role of Information Redundancy}

We wish to compare $\Gamma_{i, f}$ and $\Gamma_{i, r}$ for the purpose of determining the superior form of risk transfer, that yielding the highest expected payoff to the insurer. There are no general results for this comparison, but in order to provide some intuition and illustrate some of the tradeoffs involved in the insurer's choice, we may consider the two polar cases $\gamma=0$ and $\gamma=1$, with $k=0$ and $N$ therefore large.

When the number of traders is large, competition erodes trading profits, and informed traders do not acquire information beyond $1 / \bar{v}$. Nevertheless, when $\gamma=0$, there is no aggregate uncertainty for large $N$. As the price in the financial market aggregates all information, the insurer can infer from that price the exact value of $\delta$ and therefore has no need for capital, so that

$$
\Gamma_{i, f}=\bar{l}
$$

In contrast, the reinsurer is able to profit from the information he acquires, and may therefore select $v_{r}<\bar{v}$. The payoff to the insurer from using reinsurance is given by

$$
\Gamma_{i, r}=\bar{l}-\lambda\left[a_{i}(1-\bar{\tau})+a_{r} \bar{\tau}\right] \sqrt{v_{\delta}}\left[1-\frac{v_{\delta}}{v_{\delta}+v_{r}}\right]^{\frac{1}{2}}-c\left(\frac{\bar{v}}{v_{r}}-1\right)
$$

Hence, regardless of whether the reinsurer chooses to acquire information beyond $1 / \bar{v}$ or not, the insurer's payoff from using reinsurance is lower than that from using the financial 
market. Thus, as in Subrahmanyam and Titman (1999), when the correlated error term disappears $(\gamma=0)$, the stock market reveals the information about $\delta$ very precisely, and public financing dominates private financing (reinsurance in our case).

On the other hand, when $\gamma=1$, aggregate uncertainty in the financial market remains even for large $N$. Since no trader acquires information beyond $1 / \bar{v}$, the insurer's payoff from using the financial market is

$$
\Gamma_{i, f}=\bar{l}-\lambda a_{i}(1-\bar{\tau}) \sqrt{v_{\delta}}\left[1-\frac{v_{\delta}}{v_{\delta}+\bar{v}}\right]^{\frac{1}{2}}
$$

The expected payoff from using reinsurance does not depend on $\gamma$, and is therefore still given by (19). Note that since the reinsurer's incentive to acquire information is smaller than the first-best level, any information the reinsurer acquires is worth more than its cost from the insurer's point of view. Thus, the insurer's profit from using reinsurance is bounded from below by (19) with $v_{r}=\bar{v}$, i.e., one has

$$
\begin{aligned}
\Gamma_{i, r} & =\bar{l}-\lambda\left[a_{i}(1-\bar{\tau})+a_{r} \bar{\tau}\right] \sqrt{v_{\delta}}\left[1-\frac{v_{\delta}}{v_{\delta}+v_{r}}\right]^{\frac{1}{2}}-c\left(\frac{\bar{v}}{v_{r}}-1\right) \\
& >\bar{l}-\lambda\left[a_{i}(1-\bar{\tau})+a_{r} \bar{\tau}\right] \sqrt{v_{\delta}}\left[1-\frac{v_{\delta}}{v_{\delta}+\bar{v}}\right]^{\frac{1}{2}}
\end{aligned}
$$

Thus, when $\gamma=1$, two opposing effects operate. On the one hand, the (potentially) higher quality of the information in the case of reinsurance favors reinsurance over the financial market. On the other hand, the zero net cost of capital of the financial market favors the financial market over reinsurance. Which effect dominates determines the optimal form of risk transfer. It is interesting to contrast these results with those of Subrahmanyam and Titman (1999). In their model, when costly information is perfectly correlated across agents, private financing (reinsurance in our case) is always used because it avoids the duplication of effort in information production that arises in the financial market. In our setting, the financial market may nevertheless be used because of its lower cost of capital.

\section{Determinants of the Preferred Form of Risk Transfer}

In order to gain greater insights into how the different parameters affect the preferred form of risk transfer, we solve the model numerically, computing the expected payoff of 
the insurer from transferring risk both to the financial market and to the reinsurer. The payoff from transferring risk to the financial market is obtained by first determining the optimal amount of information acquisition by each informed trader, $v$, using the first-order condition (10), taking the number of traders $N$ as given. The number of traders in equilibrium is then determined as the largest value of $N$ for which the traders' expected profit (11), given their optimal information acquisition strategy $v$, is nonnegative. Finally, given $N$ and $v$, the insurer's payoff is computed using (16). Similarly, the insurer's payoff from transferring risk to the reinsurer is obtained by first determining the reinsurer's optimal information acquisition strategy $v_{r}$ using (15). The insurer's payoff is then obtained by inserting the optimal $v_{r}$ into (17).

Before analyzing the impact of the different parameters on the preferred form of risk transfer, we solve the model for parameter values computed from information communicated to us by a member of the Risk Management department of Swiss Re, the world's largest reinsurance company. We view these values as loosely representing current assessment of the distribution of losses and the information about such losses for a typical natural catastrophe event. The values are ( $m$ denotes millions): $\bar{l}=-500 m, \sqrt{v_{\delta}}=1,600 m$, $\sqrt{\bar{v}}=1,000 m, \bar{\tau}=0.5, a_{r}=0.05, k=5 m$, and $c=6 m$. To help interpret the parameter $c$ that indexes the variable cost of acquiring information, note that a value of $6 \mathrm{~m}$ implies that the variable cost of halving the standard deviation of the error in the information from $\sqrt{\bar{v}}=1,000 m$ to $\sqrt{v}=500 m$ is $18 m$.

We set $\lambda=2.5$, implying that the insurer and the reinsurer hold enough capital to cover losses with a probability of slightly over 99\%. Using the results of Fama and French (1997), we set $a_{i}=0.06 .{ }^{16}$ Finally, reflecting the lack of trading in catastrophe derivatives, we set $\sqrt{v_{z}}=1 \mathrm{~m}$ : noise traders' demand has standard deviation equal to $0.2 \%$ of expected loss.

Thus, in our base case, losses associated with catastrophes are large and highly uncertain; the fixed and variable costs of acquiring information are high; the standard deviation

\footnotetext{
${ }^{16}$ Fama and French (1997) do not provide separate figures for the reinsurance industry. Information provided by Swiss Re suggests that reinsurers have a 100bp cost of capital advantage over insurers.
} 
of noise trader demand is low; and acquiring information at the level $1 / \bar{v}$ permits a near halving of the uncertainty about losses.

The results of our base case are shown in Figure 1, which presents the model's solution as a function of the degree of information redundancy, $\gamma$. Specifically, the six panels in the figure report (1) the number of informed traders, $N,(2)$ the (inverse) quality of the information acquired, $\sigma \equiv \sqrt{v}$ for the financial market and $\sigma_{r} \equiv \sqrt{v_{r}}$ for reinsurance, (3) the (inverse) quality of the information available to the insurer, $S D[\delta \mid Q]$ for the financial market and $S D\left[\delta \mid i_{r}\right]$ for reinsurance, (4) the total information acquisition cost, $N(c(\bar{v} / v-1)+k)$ for the financial market and $c\left(\bar{v} / v_{r}-1\right)+k$ for reinsurance, $(5)$ the total capital cost, $\lambda a_{i}(1-\bar{\tau}) S D[\delta \mid Q]$ for the financial market and $\lambda\left[a_{i}(1-\bar{\tau})+a_{r} \bar{\tau}\right] S D\left[\delta \mid i_{r}\right]$ for reinsurance, and (6) the payoffs to the insurer from both forms of risk transfer, $\Gamma_{i, f}$ and $\Gamma_{i, r}$.

Figure 1 reveals that reinsurance dominates the financial market for all values of $\gamma$. The reason is that the financial market's capital cost advantage is not sufficient to offset its information cost disadvantage. The large information cost disadvantage arises from the combination of the large fixed information acquisition cost of $5 \mathrm{~m}$ and the large number of traders (between 15 and 30 depending on $\gamma$ ) that choose to become informed in the financial market, resulting in total information acquisition costs of about $150 \mathrm{~m}$ (versus about $10 \mathrm{~m}$ for reinsurance). The financial market's capital cost advantage ranges from about $50 \mathrm{~m}$ for $\gamma=0$ to about $20 m$ for $\gamma=1$. It represents the net impact of two effects. First, the capital cost for the fraction of risk transferred is zero for the financial market and $a_{r}$ for reinsurance; this first effect unambiguously favors the financial market. Second, the quality of the information produced affects the amount of costly capital that the insurer must hold. Although the reinsurer acquires more precise information than individual informed traders in the financial market, for $\gamma<0.5$, information acquisition by multiple traders yields better quality information than reinsurance, allowing the insurer to hold less capital than he would with reinsurance. When the degree of redundancy in the information produced is large $(\gamma>0.5)$, the opposite holds.

It is instructive to consider the impact of the degree of information redundancy $\gamma$. 
Although $\gamma$ does not affect the reinsurer's information acquisition strategy and the cost of using reinsurance (see Section 1), it does affect information production in the financial market and the cost of using it. The results in Figure 1 show that as $\gamma$ increases, the number of traders decreases (because expected profit per trader falls), but the quality of the information produced by each trader increases. Overall, an increase in $\gamma$ causes total information acquisition costs to rise, but the quality of the information available to the insurer to deteriorate. This causes reinsurance to dominate more strongly, the larger $\gamma$.

Summarizing, Figure 1 shows that when the fixed information acquisition cost $k$ is large, reinsurance is preferred because the insurer would pay for this cost multiple times if he selected the financial market. For low $\gamma$, the financial market does produce better information than reinsurance, but it is subject to a Hirshleifer effect in the sense that the extra information produced is not worth its cost. When the degree of redundancy in the information is large, however, the financial market is unable to produce better quality information than the reinsurer, in spite of the larger information acquisition costs - the reinsurer's information production is much more efficient because it avoids duplication.

What would it take for the financial market to dominate reinsurance? From the above discussion, one factor that could help is a lower fixed cost of information acquisition, $k$. Granted, a lower $k$ would increase the number of informed traders, but it may decrease the product $N k$. Figure 2 shows the solution of the model for $k=0.1 m$ (for each of the settings considered in the remainder of this section, all parameter values that are not mentioned explicitly are the same as in the base case). ${ }^{17}$ Observe that for $\gamma<0.75$, the number of informed traders in the financial market is much larger than previously at about 400, and the financial market dominates reinsurance. Two factors contribute to this effect. First, although total information acquisition costs are still higher for the financial market than for reinsurance, the financial market's information cost disadvantage is much smaller than in Figure 1 at about $30 \mathrm{~m}$. Second, because the larger number of traders provides for

\footnotetext{
${ }^{17}$ Other than those in the base case, not all the parameter values we use are realistic. We use many extreme values because such values have the merit of delivering stark results, thereby clearly illustrating the comparative statics of the model.
} 
better quality information, the financial market's capital cost advantage is higher than in the base case, ranging from $70 \mathrm{~m}$ for $\gamma=0$ to $30 \mathrm{~m}$ for $\gamma=0.75$. Observe also that for $\gamma<0.6$, the financial market provides better information than reinsurance. In contrast to the situation in Figure 1, however, the extra information is worth the extra cost because of the low $k$.

The situation when $\gamma>0.75$ is very different: informed traders acquire information beyond $1 / \bar{v}$, the number of informed traders falls sharply, and the performance of the financial market deteriorates significantly. The reason is that although not very valuable because redundant, information beyond $1 / \bar{v}$ is very costly to acquire: when $k$ is much lower than $c$, it is cheaper to have numerous people buy imprecise information than have few people acquire precise information. However, when $\gamma>0.75$, the financial market produces the second outcome. This makes the use of the financial market prohibitively costly. Granted, the reinsurer improves the quality of his information even further than the traders in the financial market and does so at significant cost. However, that cost is incurred only once-reinsurance avoids the duplication in information production that plagues the financial market for large $\gamma$ because of the large variable cost $c$.

Figure 2 considered a situation where the fixed cost $k$ was much smaller than the variable $\operatorname{cost} c$. Figure 3 shows the model's solution for the opposite situation, with $c=$ $0.12 m$ and $k=5 \mathrm{~m}$. In this setting, the cost structure is such that it is much more efficient for a single agent to acquire very precise information than for numerous agents to pay the fixed cost $k$ and acquire relatively imprecise information. Reflecting this fact, reinsurance provides better information than the financial market for all $\gamma$, at a much lower cost. The information provided by reinsurance is more precise than that provided by the financial market to such an extent that reinsurance also has a capital cost advantage over the financial market (despite the reinsurer's positive cost of capital $a_{r}$ ). Thus, for low $c$ and large $k$, reinsurance strongly dominates the financial market for all $\gamma$.

The intuition that the ratio $c / k$ constitutes a key determinant of the preferred form of risk transfer is confirmed in Figure 4, which considers the situation where both $c$ and $k$ are 50 times smaller than in the base case, i.e., setting $c=0.12$ and $k=0.1$. Note that 
except for very low values of $\gamma$, the quality of the information provided by reinsurance exceeds that provided by the financial market. Furthermore, and as in Figure 1, the total information acquisition cost is much higher for the financial market than for reinsurance. As a result, and as in the base case, reinsurance dominates the financial market for all $\gamma$.

The implication of Figures $2-4$ is that two characteristics of information production favor the financial market over reinsurance: highly convex information production costs (in our context, variable costs $c$ that exceed fixed costs $k$ ), and low redundancy in information production $\gamma$. The first makes it cost-efficient to divide information acquisition among many agents; the second ensures that duplication in information production is not a concern. The importance of information redundancy and information acquisition costs for the choice between public and private financing has already been analyzed by Subrahmanyam and Titman (1999). What our analysis reveals is that in addition to the level of information acquisition costs, their convexity is critical for this decision. The consequence is that technological innovations in information production that affect fixed and variable information production costs differently impact the preferred form of risk transfer: innovations that reduce fixed costs favor the financial market, while innovations that reduce variable costs favor reinsurance.

There is a widespread view that the presence of numerous hedgers and liquidity traders supports the use and development of financial markets. ${ }^{18}$ In order to determine whether this is indeed the case, consider the effect of increasing the volatility of noise trader demand to $\sqrt{v_{z}}=5$, five times its initial value, while keeping all other parameters as in the base case. The results are reported in Figure 5. The increased presence of liquidity traders stimulates both the number of traders in the financial market and the quality of the information that each trader acquires to such an extent that the quality of the information reflected in the price exceeds that provided by reinsurance regardless of the degree of information redundancy. Interestingly, for $\gamma>0.6$, each trader even acquires more precise information than the reinsurer. Although the increased information acquisition in the financial market is favorable from a capital cost perspective, the cost of the information

\footnotetext{
${ }^{18}$ See for example Cuny (1993).
} 
produced is prohibitively large at about $500 m$, illustrating the Hirshleifer effect in a very stark way. Thus, rather than making the financial market perform better, the presence of numerous hedgers and liquidity traders causes reinsurance to be preferred. The implication is that in order for risk transfer through the financial market to be advantageous, it may be necessary to restrict rather than encourage the participation of noise traders in these markets. Limited noise trader participation may account for the relative success of offexchange, privately placed catastrophe bonds mentioned in the introduction.

What does it take for the financial market to dominate reinsurance when the variability of hedging demand is large? The preceding analysis suggests that a very low fixed cost $k$ may achieve this result, and Figure 6 , which uses $\sqrt{v_{z}}=5$ and $k=0.001 \mathrm{~m}$, reveals that this is indeed the case. Observe that the financial market dominates reinsurance for $\gamma<0.4$, i.e., for values of $\gamma$ for which the number of traders is extremely large at almost 30,000 , but none of the traders acquires information beyond $1 / \bar{v}$. In spite of the fact that no trader acquires information beyond $1 / \bar{v}$, for low $\gamma$, the large number of traders makes the information contained in the price extremely precise. This reduces the capital cost of using the financial market below that of using reinsurance. As soon as individual traders begin acquiring information beyond $1 / \bar{v}$, however, total information acquisition costs in the financial market become prohibitively large, and reinsurance is preferred. Thus, the picture that emerges from Figure 6 is that when hedging demand is highly variable, the financial market dominates only if both the fixed cost of information acquisition and the degree of information redundancy are small—-these are the same factors that were identified in Figures 2-4, but the required values become more extreme, the larger $\sqrt{v_{z}}$.

The preceding analysis reveals that low noise trading favors the financial market because it limits informed traders' ability to profit from the information they acquire, reducing the severity of the Hirshleifer effect. Intuitively, one could expect the same effect to arise if the prior uncertainty about the loss, $\sqrt{v_{\delta}}$, is small. Figure 7 , which shows the solution of the model when the uncertainty about the loss is reduced to $\sqrt{v_{\delta}}=250$, confirms this intuition. Limited gain opportunities from trading attract fewer informed traders in the financial market, significantly reducing its information cost disadvantage compared to the 
base case. At the same time, reflecting the fact that when the uncertainty about the loss is small, there is little gain from reducing it, the reinsurer does not acquire information beyond $1 / \bar{v}$. Although the insurer's payoff improves both for the financial market and for reinsurance compared to the base case, the financial market's performance improvement is stronger. Thus, paradoxically, phenomena that lead to an increase in loss uncertainty, such a global warming, may constitute an opportunity rather than a threat for reinsurance companies.

Note that the small initial uncertainty about the loss causes the payoff from using the financial market in Figure 7 to be increasing in $\gamma$. The reason is that as $\gamma$ increases, the fall in the number of traders produces savings in information acquisition costs that significantly exceed the increase in capital cost caused by the deterioration in information quality - when $\sqrt{v_{\delta}}$ is low, the insurer does not need to hold much capital anyway. ${ }^{19}$

Contrasting Figures 1 and 2 revealed that a low fixed cost of information acquisition $k$ favors the financial market. Since $k$ is the cost of obtaining information of precision $1 / \bar{v}$, one could expect a lower $\bar{v}$ to favor the financial market as well. Figure 8, which shows the model's solution for $\sqrt{\bar{v}}=200$, reveals that this is not the case. The intuition for this result is quite simple: when $\bar{v}$ is small, information acquisition by a single agent produces a relatively precise estimate of the value of the loss. It is therefore not worth paying the cost $k$ multiple times (the outcome in the financial market), and reinsurance dominates. Note that in spite of its lower information acquisition costs, in the situation considered in Figure 8, reinsurance provides significantly better information than the financial market: noise trading garbles the information conveyed by the price in the financial market. As a result, reinsurance's capital cost disadvantage is tiny.

Figure 9 reports the model's solution when the fraction of risk ceded is increased to $\bar{\tau}=0.8$. As expected, a higher $\bar{\tau}$ stimulates information acquisition both for the financial market and for reinsurance. Interestingly, the increase in the information produced in the financial market occurs both through the number of traders (which, for low $\gamma$, increases

\footnotetext{
${ }^{19}$ Further computations, not reported in a figure for brevity, reveal that for very large values of $a_{i}$, the insurer's payoff from using the financial market is decreasing in $\gamma$ as it was in previous figures.
} 
from about 30 in the base case to over 45 here) and through the precision of the information that each trader acquires. The overall impact of the increased information acquisition is a sizable widening of the financial market's information cost disadvantage to over $200 \mathrm{~m}$, with the consequence that reinsurance dominates even more clearly than in the base case. For instance, for $\gamma=0$, the insurer is about $140 \mathrm{~m}$ better off using reinsurance than using the financial market, versus about $90 \mathrm{~m}$ in the base case. For $\gamma=1$, the payoff differential has widened from about $130 \mathrm{~m}$ to about $190 \mathrm{~m}$.

How does the insurer's capital cost $a_{i}$ affect the preferred form of risk transfer? Obviously, an increase in $a_{i}$ has no effect on the quality of the information produced by the financial market and by the reinsurer. However, a larger $a_{i}$ makes economizing on costly capital more important and therefore favors the form of risk transfer that provides better quality information. This effect is apparent in Figure 10, which shows the model's solution for $a_{i}=0.2$. Although information production and the financial market's information cost disadvantage are the same as in the base case, the financial market's capital cost advantage differs. For $\gamma<0.5$, the financial market provides better information than reinsurance, and the capital cost advantage is larger than in the base case. In contrast, for $\gamma>0.5$, reinsurance provides better information than the financial market, and the capital cost advantage is much smaller than in the base case - for $\gamma=1$, it even vanishes. Thus, in this example, although reinsurance still dominates for all $\gamma$, the financial market performs better than in the base case for $\gamma<0.5$ and worse for $\gamma>0.5$.

Durbin (2001) and Froot (2001) suggest that a prior catastrophe that depletes the capital of the reinsurance industry and increases the reinsurer's capital cost $a_{r}$ tends to favor the financial market. Figure 11, which shows the model's solution for $a_{r}=0.3$, reveals that this is indeed the case. Observe that the financial market dominates for low $\gamma$, but that reinsurance still dominates for large $\gamma$. A higher $a_{r}$ causes the financial market to perform better for two reasons. The first, obvious one is that the financial market's capital cost advantage increases. The second reason is that in an attempt to keep the amount of capital under control, the reinsurer reacts to the increased capital cost by acquiring very precise information - in the example in Figure 11, the reinsurer spends over $50 \mathrm{~m}$ in 
information acquisition costs. This significantly reduces the financial market's information cost disadvantage.

A prior catastrophe also depletes the capital of primary insurers. Figure 12 shows the model's solution if, following a catastrophe, both the insurer's and the reinsurer's capital cost increase significantly to $a_{i}=0.36$ and $a_{r}=0.3$, respectively, six times their value in the base case. Observe that although it still performs better than in the base case, the financial market does not do as well as in Figure 11. In particular, it does not dominate reinsurance for low $\gamma$. The reason is that, as was shown in Figure 10, a large $a_{i}$ tends to favor the form of risk transfer that produces better quality information: the insurer benefits from the extremely precise information acquired by the reinsurer, which reduces reinsurance's capital cost disadvantage compared to the financial market.

Finally, observe that an increase in the stringency of capital requirements $\lambda$ has the same impact as a proportionate increase in both $a_{i}$ and $a_{r}$. For example, increasing $\lambda$ from its base case value of 2.5 to 15 while leaving $a_{i}$ and $a_{r}$ at their base case values of 0.06 and 0.05, respectively, has exactly the same effect as leaving $\lambda=2.5$ and setting $a_{i}=0.3$ and $a_{r}=0.36$, the situation considered in Figure 12. The fact that the financial market performs comparatively better than in the base case for low $\gamma$ and worse for large $\gamma$ can be understood as follows. More stringent capital requirements have no effect on information production in the financial market, but stimulate information acquisition by the reinsurer. This reduces the financial market's information cost disadvantage. At the same time, a higher $\lambda$ increases capital costs both for the financial market and for reinsurance. For each form of risk transfer, the increase is smaller, the better the quality of the information provided. For reinsurance, where the quality of information is independent of $\gamma$, this translates into a constant increase in the capital cost. For the financial market, where the quality of the information is decreasing in $\gamma$, the increase in the capital cost is more pronounced, the larger $\gamma$. For instance, in the example considered in Figure 12, reinsurance's capital cost increases to about $260 \mathrm{~m}$, compared to $70 \mathrm{~m}$ in the base case. For the financial market, the capital cost increases from about $30 \mathrm{~m}$ to $170 \mathrm{~m}$ for $\gamma=0$, and from about $50 \mathrm{~m}$ to about $310 m$ for $\gamma=1$-almost twice as much. The consequence is that for $\gamma=0$, the financial 
market's capital cost advantage has widened compared to the base case, while for $\gamma=1$, it has turned into a capital cost disadvantage.

Summarizing, the numerical analysis in this section shows that large fixed information acquisition $\operatorname{costs} k$, large redundancy in the information produced $\gamma$, large volatility of noise trading $\sqrt{v_{z}}$, large prior uncertainty about the loss $\sqrt{v_{\delta}}$, and a large fraction of risk ceded $\bar{\tau}$ tend to favor reinsurance. In contrast, a large variable cost of information acquisition $c$, large noise in the information acquired $\sqrt{\bar{v}}$, and a large reinsurer cost of capital $a_{r}$ tend to favor the financial market. An increase in the insurer's cost of capital $a_{i}$ favors the form of risk transfer that produces the most precise information. Finally, more stringent capital requirements $\lambda$ have the same effect as a proportionate increase in $a_{i}$ and $a_{r}$; they tend to favor the financial market for low $\gamma$ and reinsurance for large $\gamma$.

\section{Conclusion}

In this study, we use differences in information gathering incentives between financial markets and reinsurance companies to explain why financial markets have not displaced reinsurance as the primary risk-sharing vehicle for natural catastrophe risk, despite reinsurance's alleged inefficiency. We consider an insurance company that seeks to transfer a fraction of its natural catastrophe risk exposure either through the financial market or through traditional reinsurance. Analyzing the optimal information acquisition policy of informed traders and the reinsurer, we find that the financial market may display a Hirshleifer (1971) effect in the sense that the supply of information by informed traders is excessive relative to its value for the insurance company. Since the cost of the information produced ultimately is borne by the insurer, he favors reinsurance over the financial market.

Whether traditional reinsurance or the financial market is ultimately selected depends crucially on the information acquisition cost structure and on the degree of redundancy in the information produced. When fixed information acquisition costs are large, it is very costly to have several traders in the financial market acquire information, and reinsurance 
is preferred. When information acquisition costs are highly convex, however, decentralized information production is more efficient, and the financial market is preferred. When the degree of redundancy in the information is large, there is little value to the insurer in having several traders acquire information, and reinsurance is preferred. Conversely, when the degree of redundancy is small, having several traders acquire information is very valuable because it allows reducing residual risk drastically, and the financial market is preferred.

A further prediction of the model is that factors that limit informed traders' ability to profitably take advantage of their information - such as the presence of few noise traders only - should make the use of the financial market more likely. The limited extent of noise trading in private markets may therefore provide an explanation for the relative success of the private placement of securitized natural catastrophe risks among insurance companies, hedge funds and other institutional players. In contrast, factors that stimulate information acquisition by informed traders should favor reinsurance. One such factor is an increase in the uncertainty about losses. Thus, paradoxically, global warming and its detrimental impact on loss uncertainty may represent an opportunity for reinsurance companies, unless the financial market's expertise in modeling natural catastrophe risks improves.

This study could be extended along several dimensions. First, one could allow the insurer to use both reinsurance and the financial market. Second, one could explicitly account for the moral hazard issues that prevail in the reinsurance industry in order to assess whether the magnitude of the associated costs would be sufficient to reverse the conclusion that reinsurance tends to dominate the financial market. Third, one could construct a dynamic version of the model incorporating the learning process that takes place in the financial market and in the reinsurance industry in order to assess whether greater familiarity with the assessment of catastrophe risks could, over time, make the use of the financial market more viable. Finally, one could investigate whether there are differences in the degree of information redundancy across the various types of natural catastrophesearthquakes, floods, hurricanes, windstorms - in order to assess whether some of these risks are more amenable to securitization and successful exchange trading than others. 


\section{Appendix}

\section{Determination of Optimal Demand $x_{n}$}

Recall from (4) that trader $n$ chooses his optimal demand $x_{n}$ by solving

$$
\max _{x_{n}} E\left[x_{n}\left[\bar{\tau} \delta-\zeta\left(x_{n}+\sum_{\substack{m=1 \\ m \neq n}}^{N} \kappa i_{m}+z\right)\right] \mid i_{n}\right]
$$

Substituting $i_{m}=\delta+\sqrt{v}\left(\gamma \xi+\sqrt{1-\gamma^{2}} \epsilon_{m}\right)$ and using the fact that $z$ and $\epsilon_{m}$ are independent of $i_{n}$, this expression can be rewritten as

$$
\begin{aligned}
& \max _{x_{n}} x_{n}\left[\bar{\tau} E\left[\delta \mid i_{n}\right]-\zeta\left(x_{n}+(N-1) \kappa E\left[\delta \mid i_{n}\right]+(N-1) \kappa \sqrt{v} \gamma E\left[\xi \mid i_{n}\right]\right)\right] \\
= & \max _{x_{n}} x_{n}\left[(\bar{\tau}-\zeta(N-1) \kappa) \frac{v_{\delta}}{v_{\delta}+v_{n}} i_{n}-\zeta x_{n}-\zeta(N-1) \kappa \gamma^{2} \frac{\sqrt{v_{n}} \sqrt{v}}{v_{\delta}+v_{n}} i_{n}\right]
\end{aligned}
$$

Differentiating with respect to $x_{n}$ and solving yields

$$
x_{n}=\frac{1}{2 \zeta} \frac{\bar{\tau} v_{\delta}-\zeta(N-1) \kappa\left(v_{\delta}+\gamma^{2} \sqrt{v_{n}} \sqrt{v}\right)}{v_{\delta}+v_{n}} i_{n}
$$

which is optimal demand (5) in the text.

\section{Determination of the Optimal Information Acquisition Policy $v_{n}$}

Recall from (7) that trader $n$ chooses his optimal information acquisition policy $v_{n}$ by solving

$$
\max _{v_{n}} E\left[E\left[x_{n}\left[\bar{\tau} \delta-\zeta\left(x_{n}+\sum_{\substack{m=1 \\ m \neq n}}^{N} \kappa i_{m}+z\right)\right] \mid i_{n}\right]\right]-c\left(\frac{\bar{v}}{v_{n}}-1\right)-k
$$

Substituting $i_{m}=\delta+\sqrt{v}\left(\gamma \xi+\sqrt{1-\gamma^{2}} \epsilon_{m}\right)$ and using the fact that $z$ and $\epsilon_{m}$ are independent of $i_{n}$, this expression can be rewritten as

$$
\begin{array}{ll}
\max _{v_{n}} & E\left[x_{n}\left[(\bar{\tau}-\zeta(N-1) \kappa) \frac{v_{\delta}}{v_{\delta}+v_{n}} i_{n}-\zeta x_{n}-\zeta(N-1) \kappa \gamma^{2} \frac{\sqrt{v_{n}} \sqrt{v}}{v_{\delta}+v_{n}} i_{n}\right]\right] \\
& -c\left(\frac{\bar{v}}{v_{n}}-1\right)-k
\end{array}
$$


From (24), we have

$$
\frac{\bar{\tau} v_{\delta}-\zeta(N-1) \kappa\left(v_{\delta}+\gamma^{2} \sqrt{v_{n}} \sqrt{v}\right)}{v_{\delta}+v_{n}} i_{n}=2 \zeta x_{n}
$$

Hence, problem (26) becomes

$$
\begin{aligned}
& \max _{v_{n}} E\left[x_{n}\left[2 \zeta x_{n}-\zeta x_{n}\right]\right]-c\left(\frac{\bar{v}}{v_{n}}-1\right)-k \\
= & \max _{v_{n}} E\left[\zeta x_{n}^{2}\right]-c\left(\frac{\bar{v}}{v_{n}}-1\right)-k
\end{aligned}
$$

Substituting $x_{n}$ from (24) and using the fact that $E\left[i_{n}^{2}\right]=v_{\delta}+v_{n}$ then yields

$$
\max _{v_{n}} \frac{1}{4 \zeta} \frac{\left(\bar{\tau} v_{\delta}-\zeta \kappa(N-1)\left(v_{\delta}+\gamma^{2} \sqrt{v_{n}} \sqrt{v}\right)\right)^{2}}{v_{\delta}+v_{n}}-c\left(\frac{\bar{v}}{v_{n}}-1\right)-k
$$

Note that the first term is decreasing in $v_{n}$, indicating that there is a benefit to improving the quality of the information.

Differentiating with respect to $v_{n}$, the first-order condition corresponding to an interior solution reads

$$
\begin{aligned}
& \frac{1}{4 \zeta} \frac{\bar{\tau} v_{\delta}-\zeta \kappa(N-1)\left(v_{\delta}+\gamma^{2} \sqrt{v_{n}} \sqrt{v}\right)}{\left(v_{\delta}+v_{n}\right)^{2}} \times \\
& \left(\zeta \kappa(N-1) \gamma^{2} \frac{\sqrt{v}}{\sqrt{v_{n}}}\left(v_{\delta}+v_{n}\right)+\left(\bar{\tau} v_{\delta}-\zeta \kappa(N-1)\left(v_{\delta}+\gamma^{2} \sqrt{v_{n}} \sqrt{v}\right)\right)\right)=c \frac{\bar{v}}{v_{n}^{2}}
\end{aligned}
$$

Imposing the symmetry conditions $\kappa_{n}=\kappa$ and $v_{n}=v$, we have

$$
\kappa=\frac{\bar{\tau} v_{\delta}}{\zeta\left[(N+1) v_{\delta}+\left(2+(N-1) \gamma^{2}\right) v\right]}
$$

Since $P=\bar{\tau} \bar{l}+\zeta Q=\bar{\tau} \bar{l}+E[\bar{\tau} \delta \mid Q], \zeta$ is the coefficient in the regression of $\bar{\tau} \delta$ on $Q$, i.e.,

$$
\zeta=\frac{\operatorname{cov}(\bar{\tau} \delta, Q)}{\operatorname{var}(Q)}=\frac{\bar{\tau} v_{\delta} \sqrt{N\left(v_{\delta}+v\right)}}{\sqrt{v_{z}}\left[(N+1) v_{\delta}+\left(2+(N-1) \gamma^{2}\right) v\right]}
$$

Inserting this expression into (31) then yields

$$
\kappa=\sqrt{\frac{v_{z}}{N\left(v_{\delta}+v\right)}}
$$

Setting $v_{n}=v$ for a symmetric equilibrium and substituting $\kappa$ and $\zeta$ from (31) and (32), the first order condition (30) becomes

$$
\frac{\bar{\tau}\left(2+(N-1) \gamma^{2}\right) \sqrt{v_{z}} v_{\delta}}{2 \sqrt{N} \sqrt{v_{\delta}+v}\left[(N+1) v_{\delta}+\left(2+(N-1) \gamma^{2}\right) v\right]}=c \frac{\bar{v}}{v^{2}}
$$

which is (10) in the text. 
Determination of Expected Profit $\Pi_{f}$

From (28), given $v_{n}=v$, the trader's expected profit is given by

$$
\Pi_{f}=E\left[\zeta x_{n}^{2}\right]-c\left(\frac{\bar{v}}{v}-1\right)-k
$$

Using (8) and (9), the first term can be rewritten as

$$
\begin{aligned}
E\left[\zeta x_{n}^{2}\right] & =\zeta \kappa^{2}\left(v_{\delta}+v\right) \\
& =\left(\frac{\bar{\tau} v_{\delta} \sqrt{N\left(v_{\delta}+v\right)}}{\sqrt{v_{z}}\left[(N+1) v_{\delta}+\left(2+(N-1) \gamma^{2}\right) v\right]}\right)\left(\frac{v_{z}}{N\left(v_{\delta}+v\right)}\right)\left(v_{\delta}+v\right) \\
& =\frac{\bar{\tau} \sqrt{v_{z}} v_{\delta} \sqrt{v_{\delta}+v}}{\sqrt{N}\left[(N+1) v_{\delta}+\left(2+(N-1) \gamma^{2}\right) v\right]}
\end{aligned}
$$

Inserting this expression into (35) yields (11). 


\section{References}

Bantwal, Vivek J. and Howard C. Kunreuther, 2000, "A Cat Bond Premium Puzzle?" Journal of Psychology and Financial Markets 1, 76-91.

Barrieu, Pauline and Henri Loubergé, 2006, "Hybrid Cat-Bonds," Working Paper.

Boot, Arnoud W.A. and Anjan V. Thakor, 1993, "Security Design," Journal of Finance 48, 1349-1378.

Cummins, J. David, David Lalonde, and Richard D. Phillips, 2004, "The Basis Risk of Catastrophic-Loss Index Securities," Journal of Financial Economics 71, 77-111.

Cuny, Charles J., 1993, "The Role of Liquidity in Futures Market Innovations," Review of Financial Studies 6, 57-78.

DeMarzo, Peter M. and J. Darrell Duffie, 1999, "A Liquidity Based Model of Security Design," Econometrica 67, 65-99.

Doherty, Neil A., 1997, "Innovations in Managing Catastrophe Risk," Journal of Risk and Insurance 64, 713-718.

Doherty, Neil A. and Harris Schlesinger, 2002, "Insurance Contracts and Securitization," Journal of Risk and Insurance 69, 45-62.

Durbin, David, 2001, "Managing Natural Catastrophe Risks: The Structure and Dynamics of Reinsurance," Geneva Papers on Risk and Insurance 26, 297-309.

Fama, Eugene F. and Kenneth R. French, 1997, "Industry Costs of Equity," Journal of Financial Economics 43, 153-193.

Froot, Kenneth A., 2001, "The Market for Catastrophe Risk: A Clinical Examination," Journal of Financial Economics 60, 529-571.

Froot, Kenneth A. and Paul J. G. O'Connell, 1997, "On the Pricing of Intermediated Risks: Theory and Application to Catastrophe Reinsurance," NBER WP 6011. 
Froot, Kenneth A., David S. Scharfstein, and Jeremy C. Stein, 1993, "Risk Management: Coordinating Corporate Investment and Financing Policies," Journal of Finance 48, 1629-1658.

Froot, Kenneth A. and Jeremy C. Stein, 1998, "Risk Management, Capital Budgeting, and Capital Structure Policy for Financial Institutions: An Integrated Approach," Journal of Financial Economics 47, 55-82.

Fulghieri, Paolo and Dmitry Lukin, 2001, "Information Production, Dilution Costs, and Optimal Security Design," Journal of Financial Economics 61, 3-42.

Gorton, Gary and George Pennacchi, 1993, "Security Baskets and Index-Linked Securities," Journal of Business 66, 1-23.

Gron, Anne and Andrew Winton, 2001, "Risk Overhang and Market Behavior," Journal of Business 74, 591-612.

Grossman, Sanford J. and Joseph E. Stiglitz, 1980, "On the Impossibility of Informationally Efficient Markets," American Economic Review 70, 393-408.

Hirshleifer, Jack, 1971, "The Private and Social Value of Information and the Reward to Inventive Activity," American Economic Review 61, 561-574.

Jaffee, Dwight M. and Thomas Russell, 1997, "Catastrophe Insurance, Capital Markets, and Uninsurable Risks," Journal of Risk and Insurance 64, 205-230.

Kyle, Albert S., 1985, "Continuous Auctions and Insider Trading," Econometrica 53, $1315-1335$.

Lakdawalla, Darius and George Zanjani, 2006, "Catastrophe Bonds, Reinsurance, and the Optimal Collateralization of Risk-Transfer," NBER WP 12742.

Milgrom, Paul R. and Robert J. Weber, 1982, "A Theory of Auctions and Competitive Bidding," Econometrica 50, 1089-1122.

Sigma, 2006, "Natural Catastrophes and Man-made Disasters in 2005," Sigma, No 2/2006, Swiss Reinsurance Company, Zurich. 
Subrahmanyam, Avanidhar, 1991, "A Theory of Trading in Stock Index Futures," Review of Financial Studies 4, 17-51.

Subrahmanyam, Avanidhar and Sheridan Titman, 1999, "The Going-Public Decision and the Development of Financial Markets," Journal of Finance 54, 1045-1082.

Swiss Re, 2002, An Introduction to Reinsurance, Swiss Re Technical Publishing, Zurich.

Swiss Re, 2006, Restoring the Faith, Swiss Re Group Knowledge \& Records Management, New Articles Bulletin, July 1, 2006. 

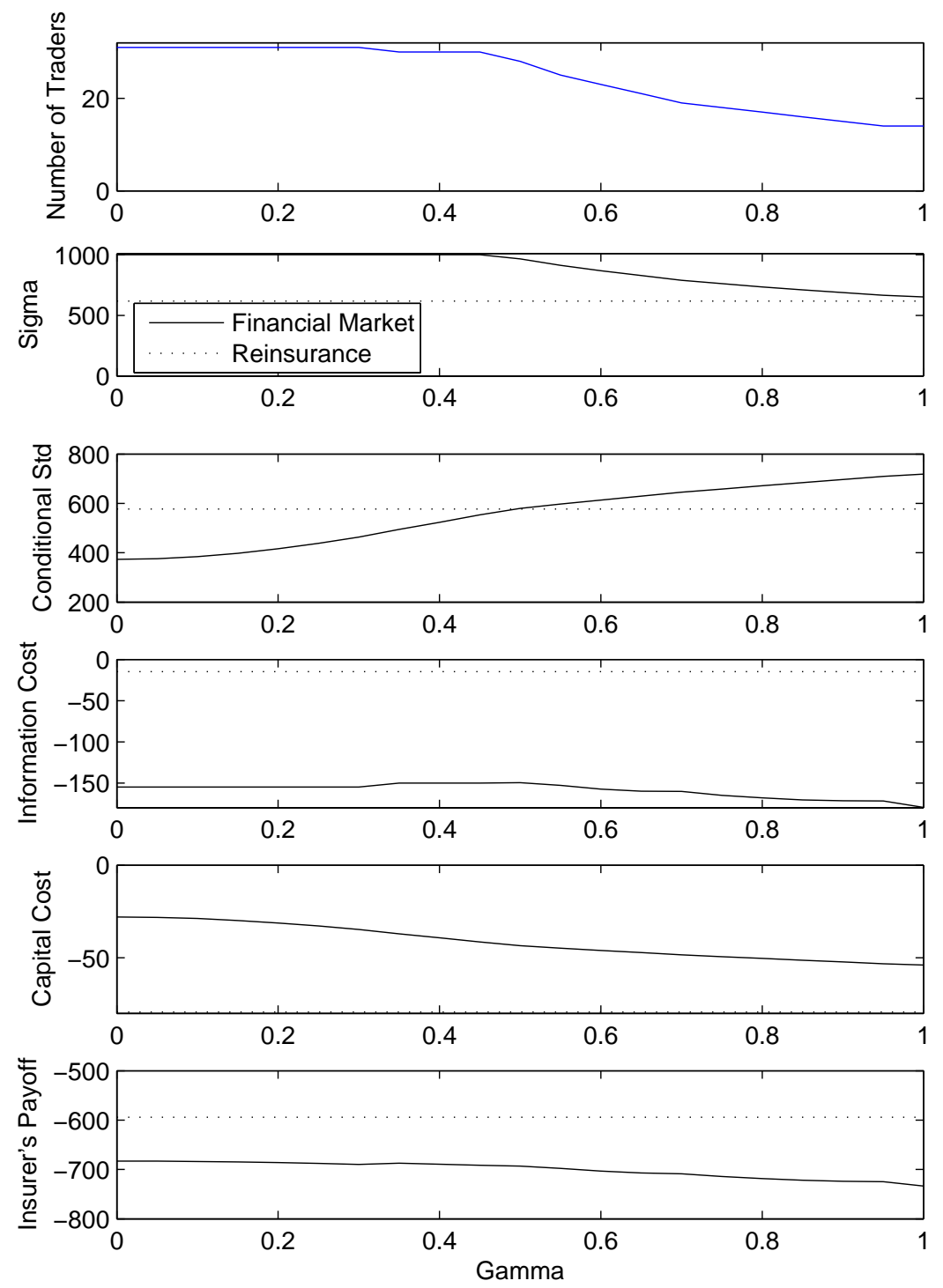

Figure 1: Solution of the model as a function of the degree of information redundancy $\gamma$ for the base case parameter values $\bar{l}=-500 \mathrm{~m}, \sqrt{v_{\delta}}=1,600 \mathrm{~m}, \sqrt{\bar{v}}=1,000 \mathrm{~m}, \sqrt{v_{z}}=1 \mathrm{~m}, \lambda=2.5$, $\bar{\tau}=0.5, a_{i}=0.06, a_{r}=0.05, k=5 \mathrm{~m}$, and $c=6 \mathrm{~m}$. The first panel shows the number of informed traders in the financial market, $N$. The second panel reports the (inverse) quality of the information acquired by the individual traders in the financial market, $\sigma=\sqrt{v}$, and by the reinsurer, $\sigma=\sqrt{v_{r}}$. The third panel reports the (inverse) quality of the information available to the insurer, $S D[\delta \mid Q]$ for the financial market and $S D\left[\delta \mid i_{r}\right]$ for reinsurance. The fourth panel reports the total information acquisition cost, $N(c(\bar{v} / v-1)+k)$ for the financial market and $c\left(\bar{v} / v_{r}-1\right)+k$ for reinsurance. The fifth panel reports the total capital cost, $\lambda a_{i}(1-\bar{\tau}) S D[\delta \mid Q]$ for the financial market and $\lambda\left[a_{i}(1-\bar{\tau})+a_{r} \bar{\tau}\right] S D\left[\delta \mid i_{r}\right]$ for reinsurance. The sixth panel shows the payoffs to the insurer from using the financial market and reinsurance, $\Gamma_{i, f}$ and $\Gamma_{i, r}$. 

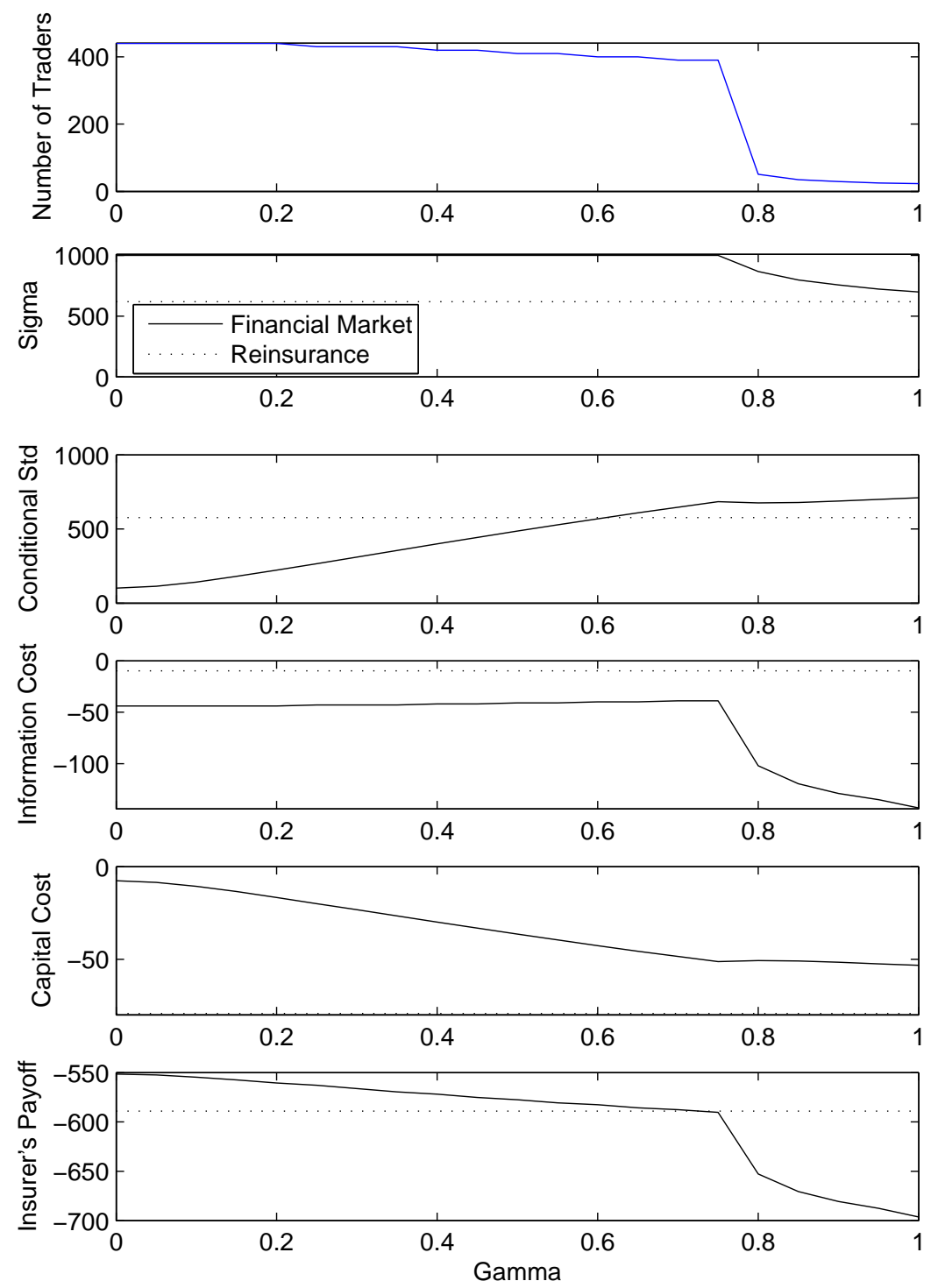

Figure 2: Solution of the model as a function of the degree of information redundancy $\gamma$ with $k=0.1$. 

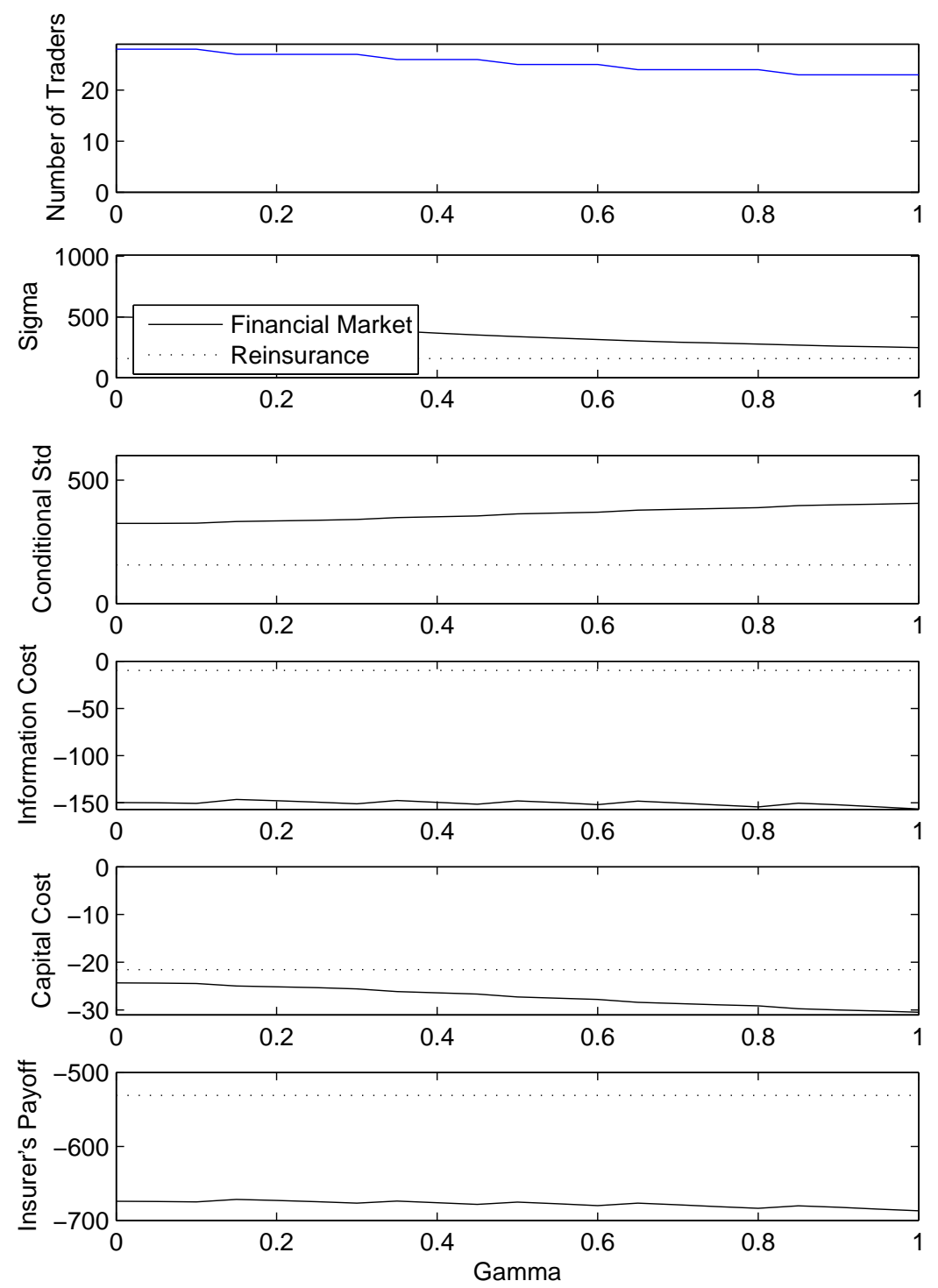

Figure 3: Solution of the model as a function of the degree of information redundancy $\gamma$ with $c=0.12$. 

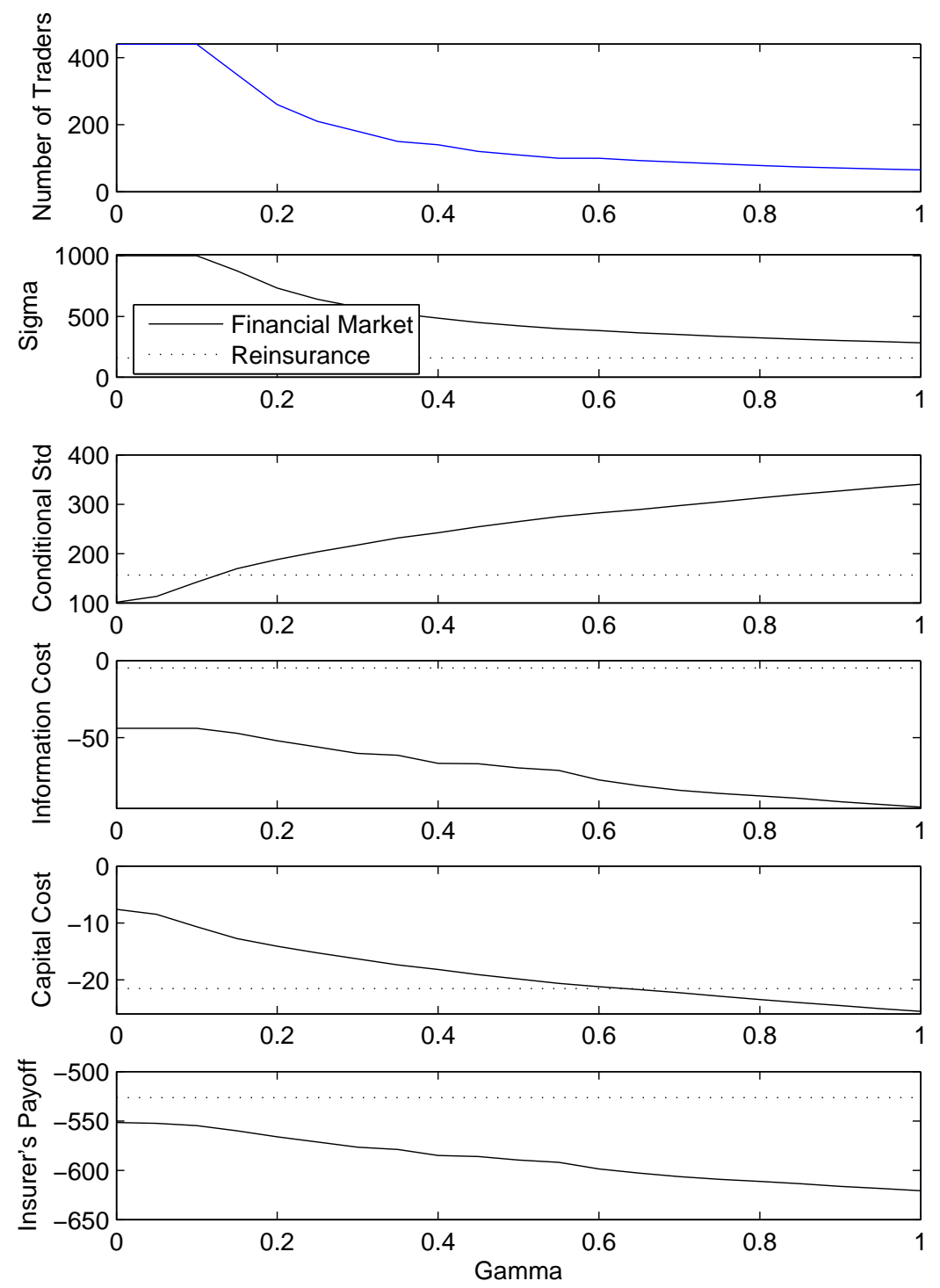

Figure 4: Solution of the model as a function of the degree of information redundancy $\gamma$ with $c=0.12$ and $k=0.1$. 

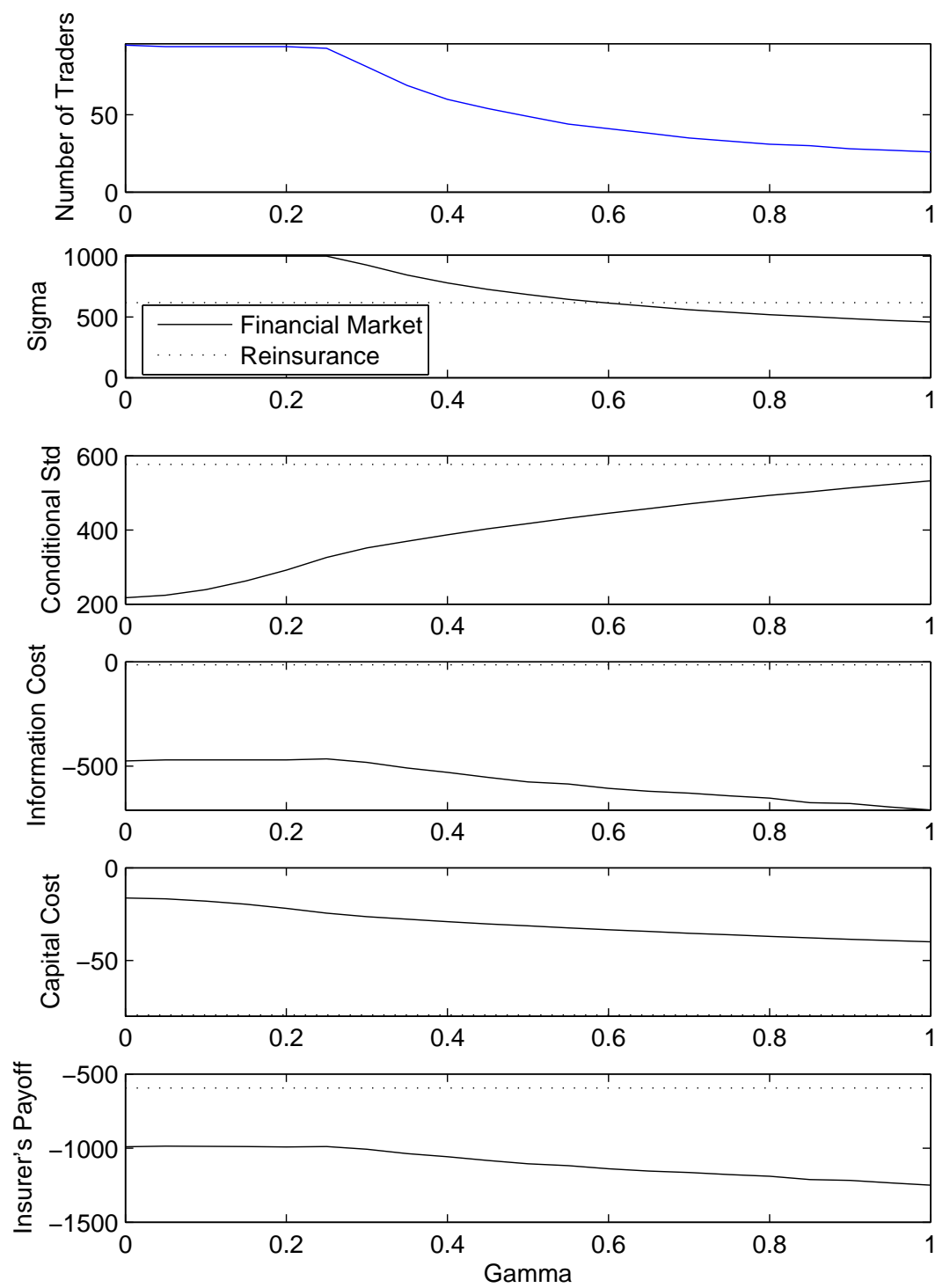

Figure 5: Solution of the model as a function of the degree of information redundancy $\gamma$ with $\sqrt{v_{z}}=5$. 

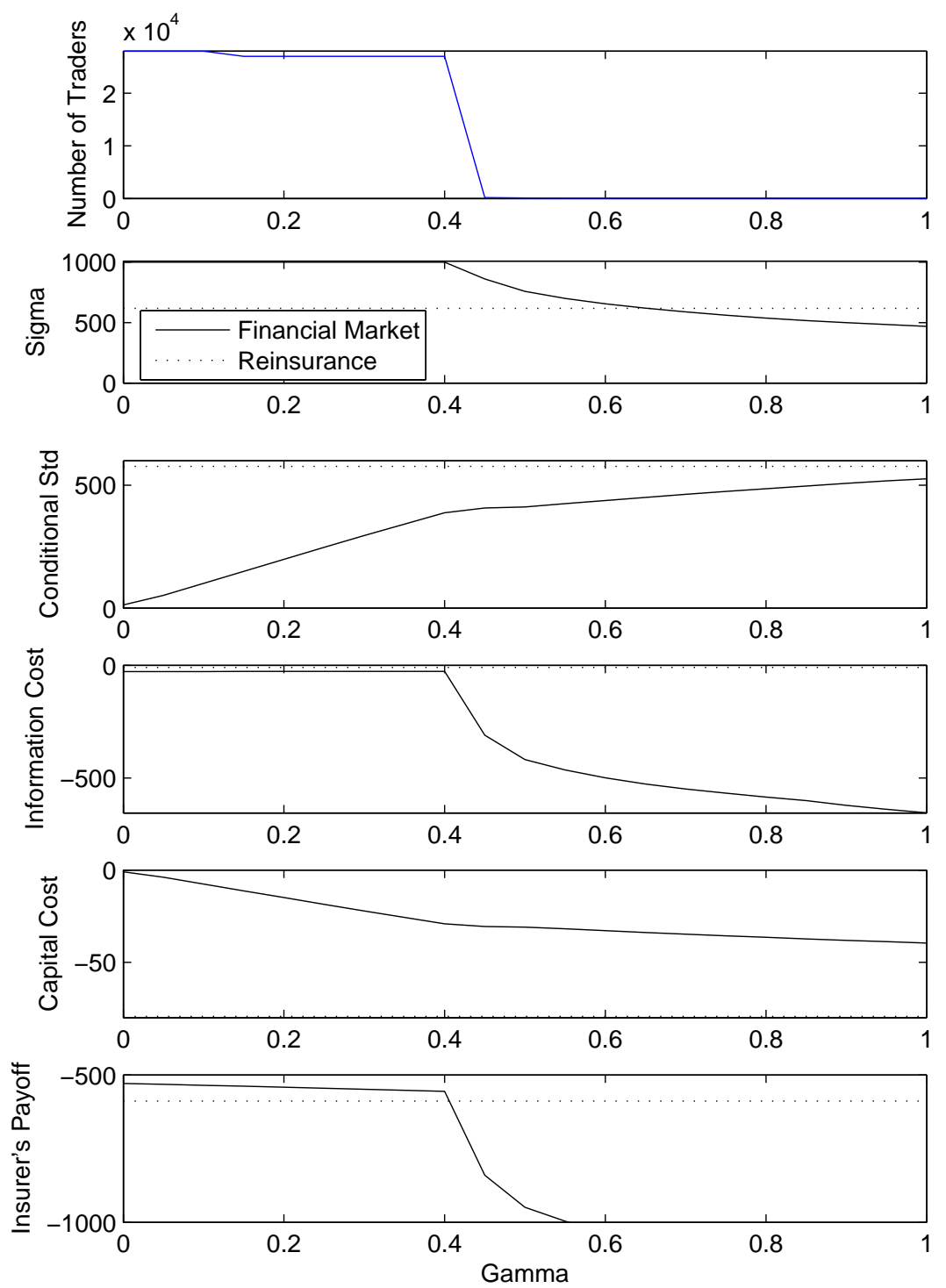

Figure 6: Solution of the model as a function of the degree of information redundancy $\gamma$ with $\sqrt{v_{z}}=5$ and $k=0.001 \mathrm{~m}$. 

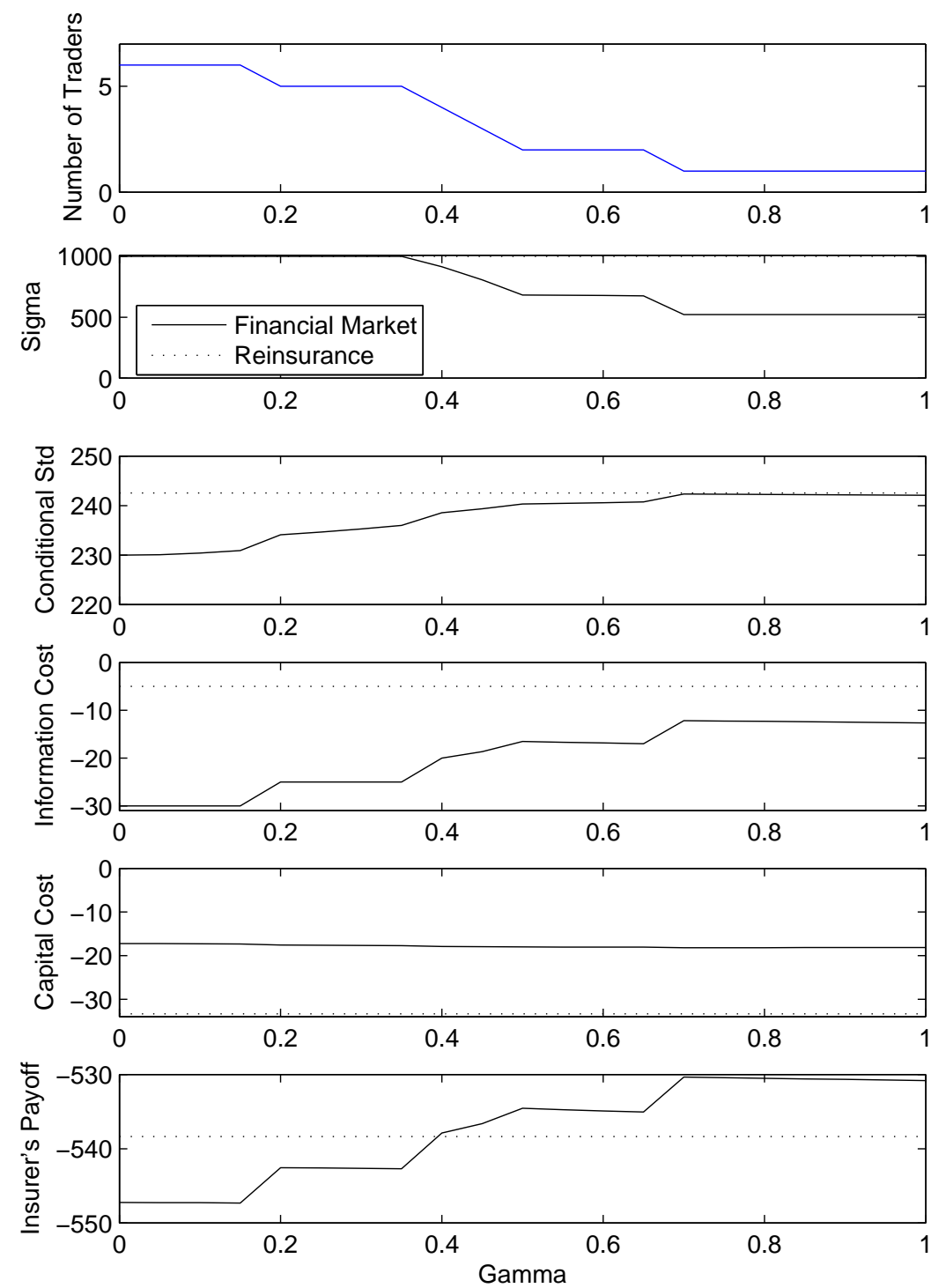

Figure 7: Solution of the model as a function of the degree of information redundancy $\gamma$ with $\sqrt{v_{\delta}}=250$. 

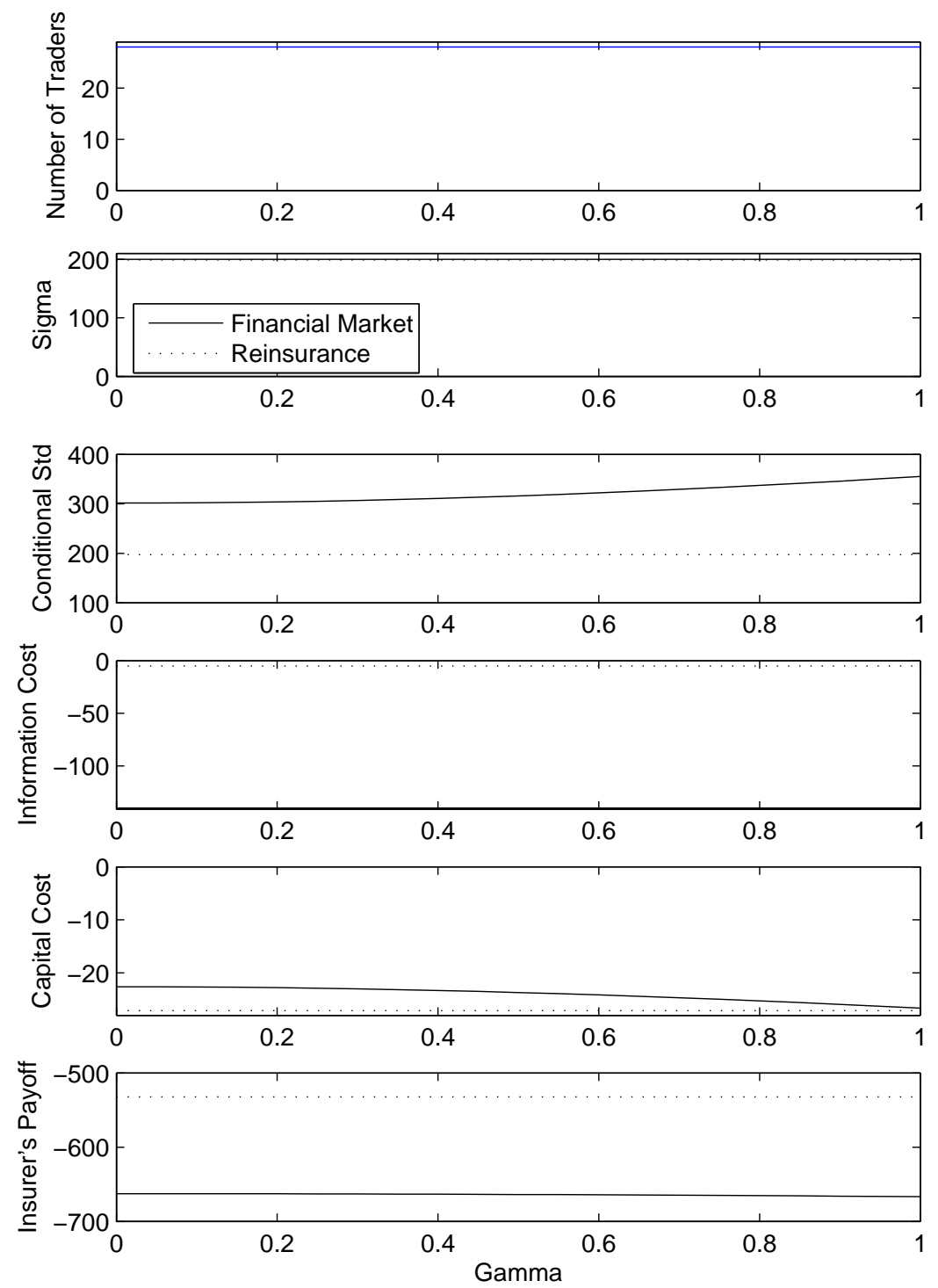

Figure 8: Solution of the model as a function of the degree of information redundancy $\gamma$ with $\sqrt{\bar{v}}=200$. 

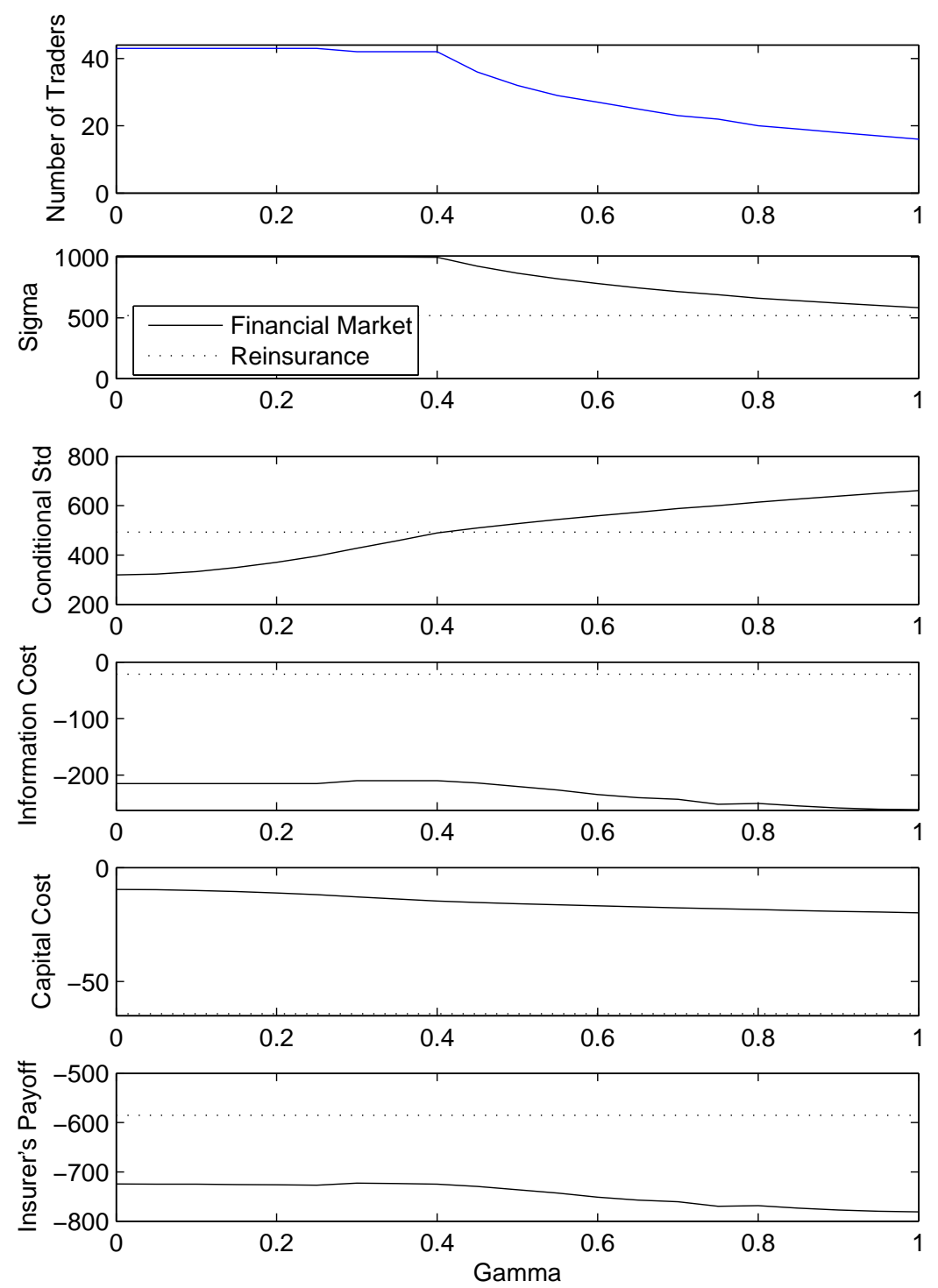

Figure 9: Solution of the model as a function of the degree of information redundancy $\gamma$ with $\bar{\tau}=0.8$. 

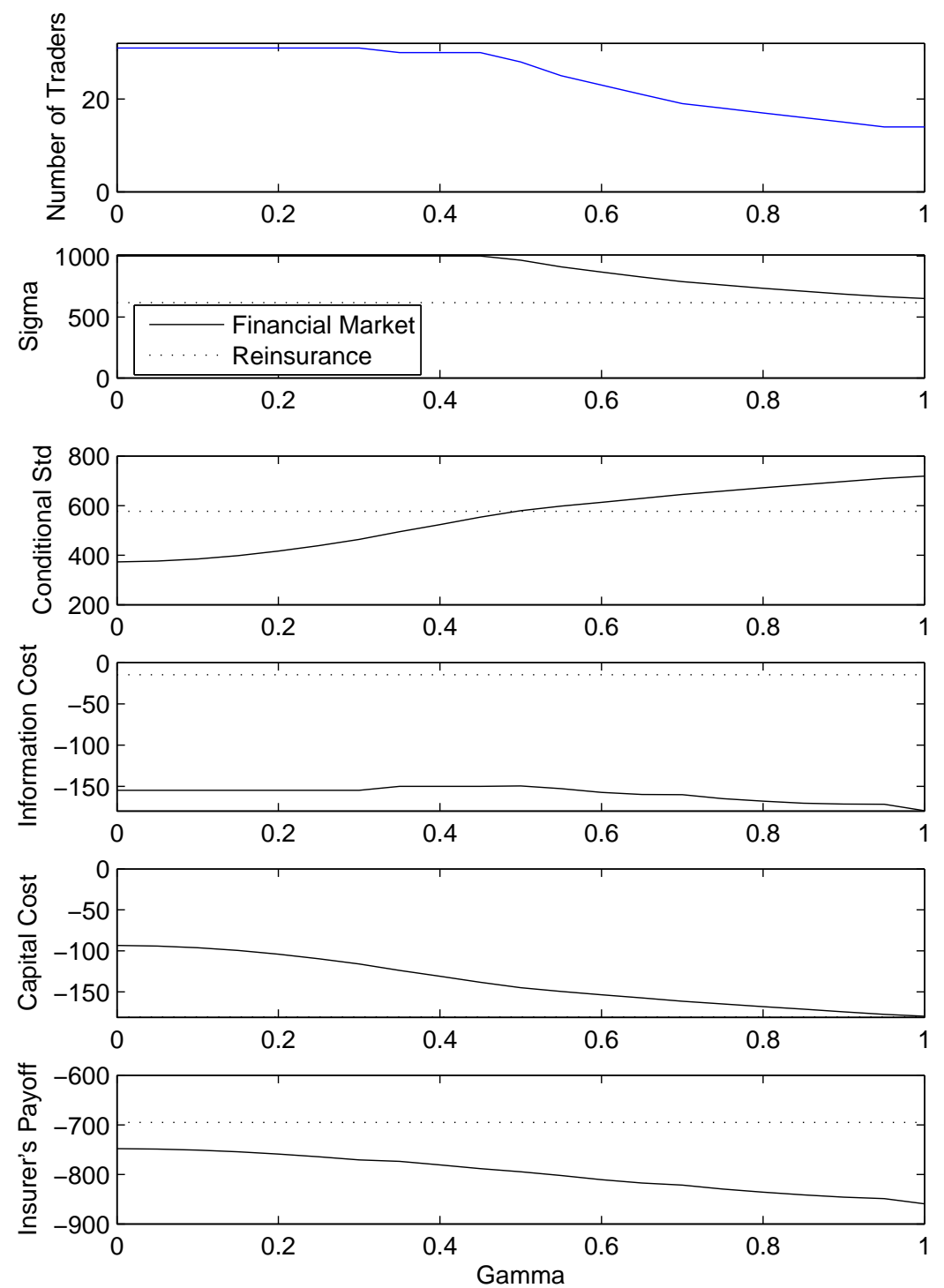

Figure 10: Solution of the model as a function of the degree of information redundancy $\gamma$ with $a_{i}=0.2$. 

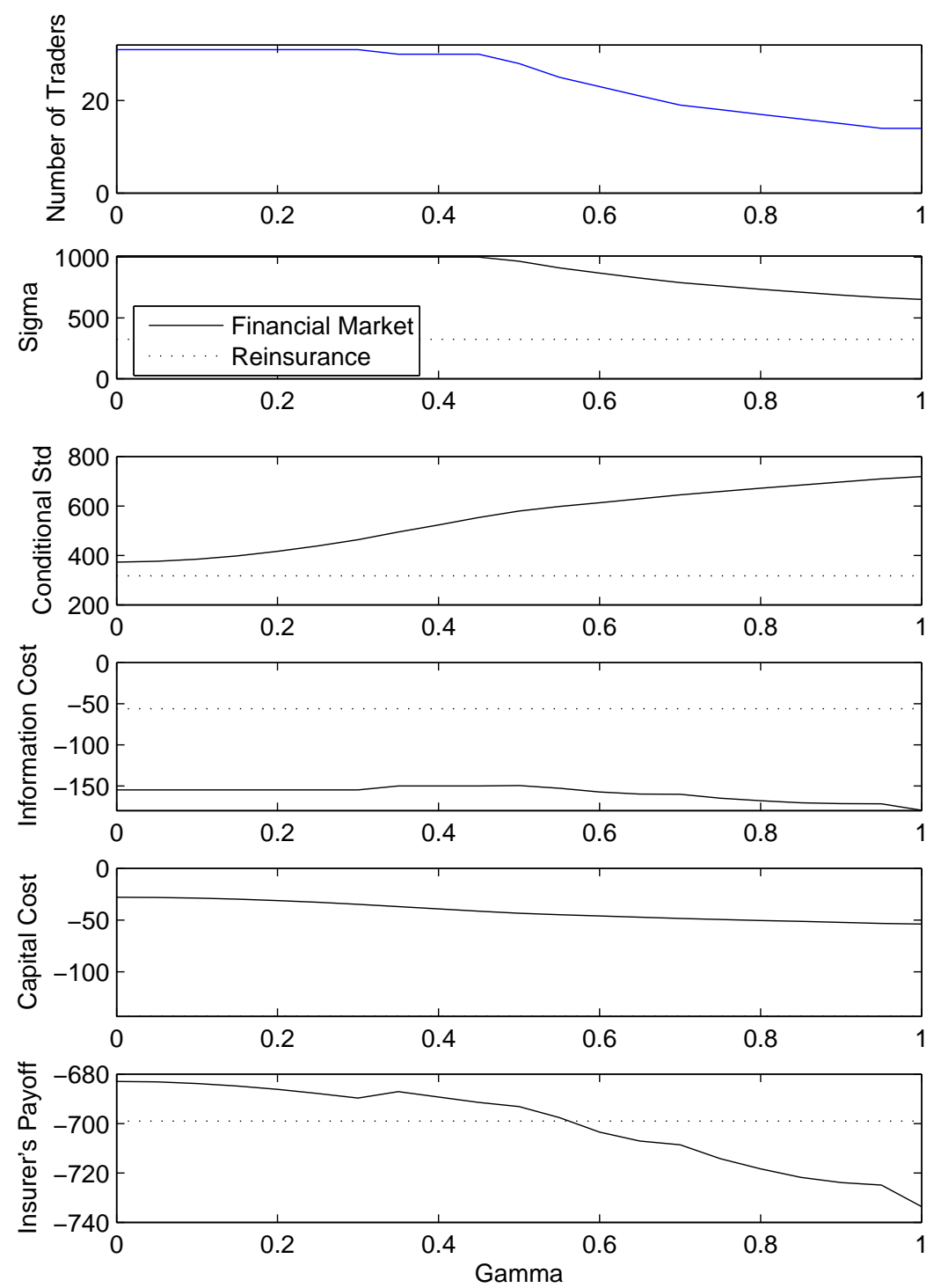

Figure 11: Solution of the model as a function of the degree of information redundancy $\gamma$ with $a_{r}=0.3$. 

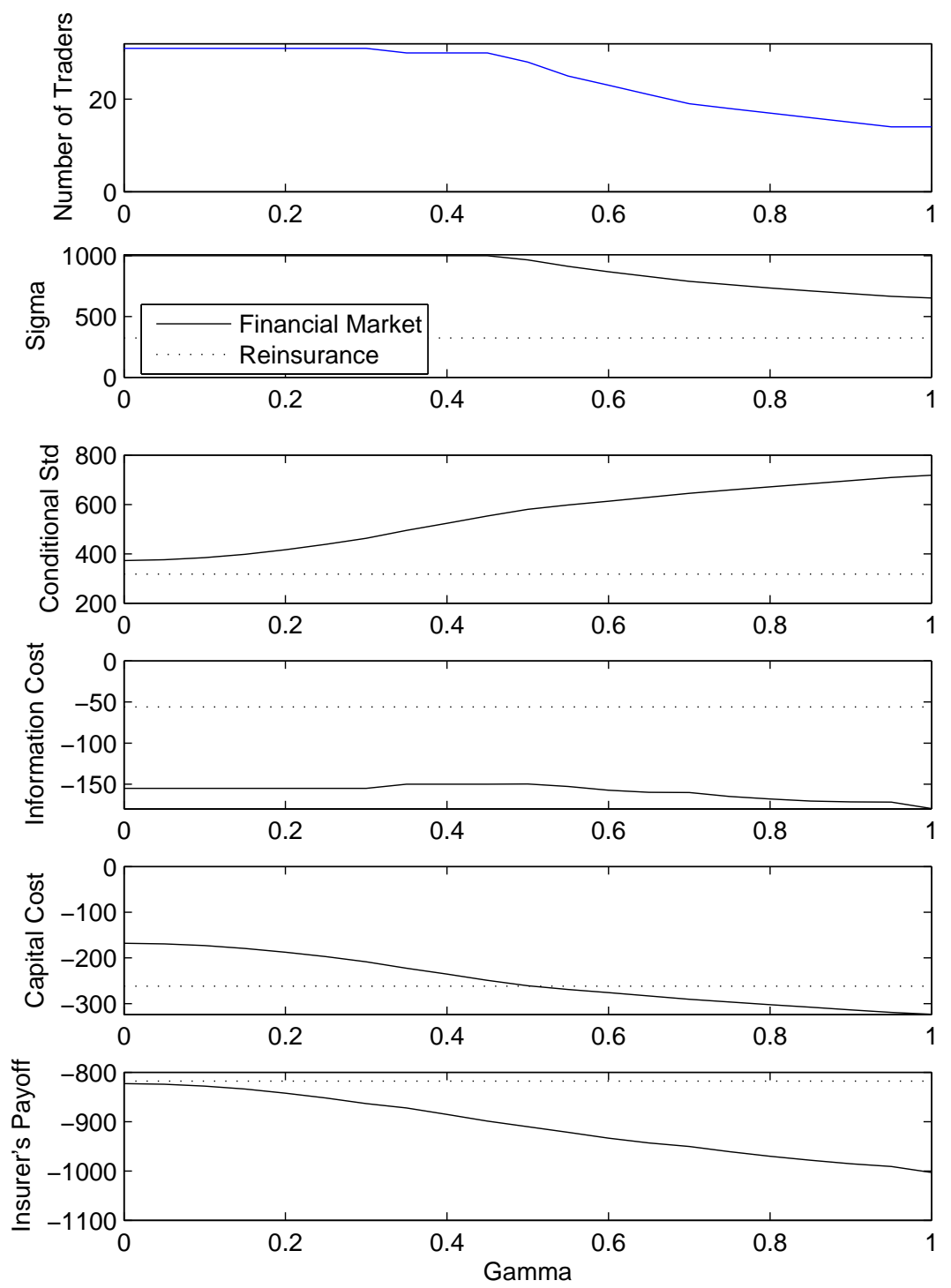

Figure 12: Solution of the model as a function of the degree of information redundancy $\gamma$ with $a_{i}=0.35$ and $a_{r}=0.3$. 